\title{
Surface Geophysical Exploration of SX Tank Farm at the Hanford Site: Results of Background Characterization with Magnetics and Electromagnetics
}

Prepared by D. Rucker, M. Levitt, B. Cubbage

hydroGEOPHYSICS, Inc.

C. Henderson

Columbia Energy \& Environmental Services, Inc.

Prepared for

Washington River Protection Solutions

Richland, WA 99352

U.S. Department of Energy Contract DE-AC27-08RV14800

EDT/ECN: DRF UC:

Cost Center: Charge Code:

B\&R Code: $\quad$ Total Pages: $\quad 55$

Key Words: $241-S X$ tank farm, 216-S-25, 216-S-8, 216-S-1, 216-S-2, electromagnetic induction, magnetic gradiometry

Abstract: This report presents the results of the background characterization of the cribs and trenches surrounding the SX tank farm.

TRADEMARK DISCLAIMER. Reference herein to any specific commercial product, process, or service by trade name, trademark, manufacturer, or otherwise, does not necessarily constitute or imply its endorsement, recommendation, or favoring by the United States Government or any agency thereof or its contractors or subcontractors.

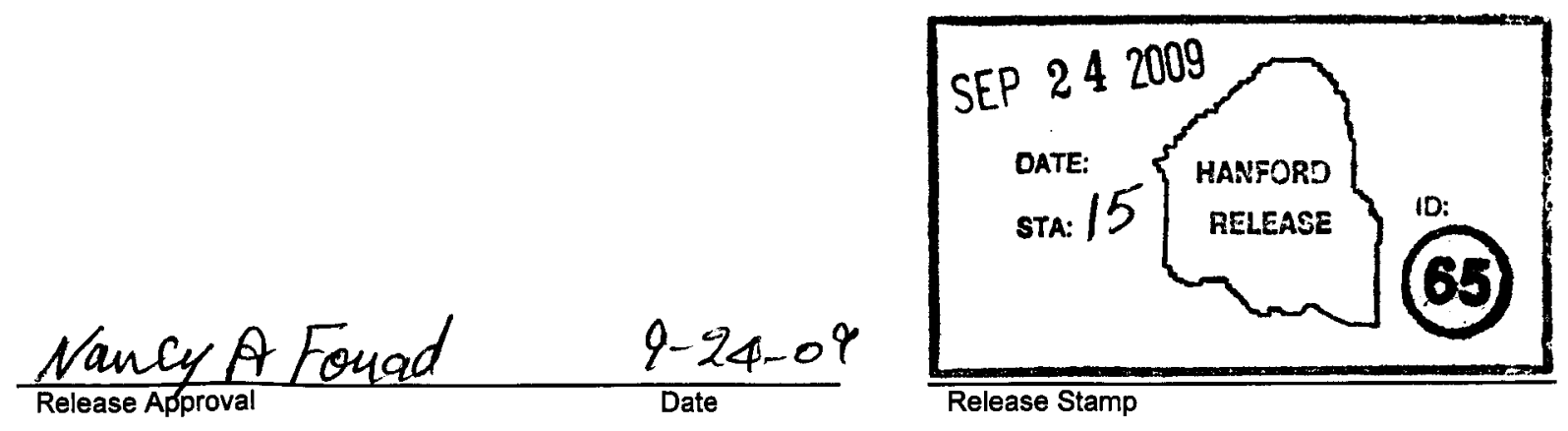

Approved For Public Release 
RPP-RPT-42512, Rev. 0

\section{EXECUTIVE SUMMARY}

This report documents the results of preliminary surface geophysical exploration activities performed between February and March 2009 at the waste management areas surrounding the SX tank farm. The SX tank farm is located in the 200 West Area of the U.S. Department of Energy's Hanford Site in Washington State. The objective of the preliminary investigation was to acquire background characterization information using magnetic gradiometry and electromagnetic induction methods to understand the spatial distribution of buried metallic objects that could potentially interfere with the results of a subsequently completed high resolution resistivity survey.

Data coverage included a total of approximately 40 acres surrounding the SX tank farm. No data were collected within in the SX tank farm as part of this survey due to the abundance of surface metal that would interfere with measurements. However, a ground penetrating radar survey was completed within the SX tank farm as part a separate background survey that is documented in RPP-RPT-38321, Surface Geophysical Exploration of S and SX Tank Farms at the Hanford Site: Results of Background Characterization with Ground Penetrating Radar. Results of the background characterization indicate that there are several areas located around the tank farms which have large metallic subsurface debris or metallic infrastructure that will likely influence the resistivity results.

Figure ES-1 shows the results of the magnetic vertical gradient response patterns in nanoTeslas. The vertical magnetic gradient reveals some linear features, exhibited by the red and blue color contours, most noticeably in the areas to the east and southeast of the SX tank farm. Areas to the south and west appear to be free from subsurface conductive infrastructure. Responses from fence posts and other above ground metal objects are present in the $216-\mathrm{S}-25$ area to the west of the SX tank farm. Areas that have no buried metal, which are referred to as background conditions, are represented by yellow hues. Areas too steep to traverse with the Geophysical Operations Cart ${ }^{\mathrm{TM}}$ (indicated by orange hatch marks) and "cave in" areas (yellow hatch marks), were not surveyed. Interpreted responses were correlated to available infrastructure maps. The location of the infrastructure was segregated relative to the ground surface (i.e., above or below ground) and interpreted subsurface infrastructure is represented by solid black lines.

Figure ES-2 shows the electrical conductivity survey results using the $10 \mathrm{kHz}$ frequency. As in Figure ES-1, the color scale was developed so that background conditions are represented by yellow colors and high conductivity features are shown in red tones. The figure shows several high conductivity regions that could be indicative of subsurface metals including steel pipes. The features correlate with the results of the magnetic survey, which provides the ability to segregate ferrous metals that will appear on the magnetic gradiometry and electromagnetic data, and non-ferrous metals that will only be visible only on the electromagnetic results.

\footnotetext{
${ }^{\mathrm{r}}$ Geophysical Operations Cart is a trademark of hydroGEOPHYSICS, Inc.
} 
Figure ES-1. Results of the Magnetic Vertical Gradient.

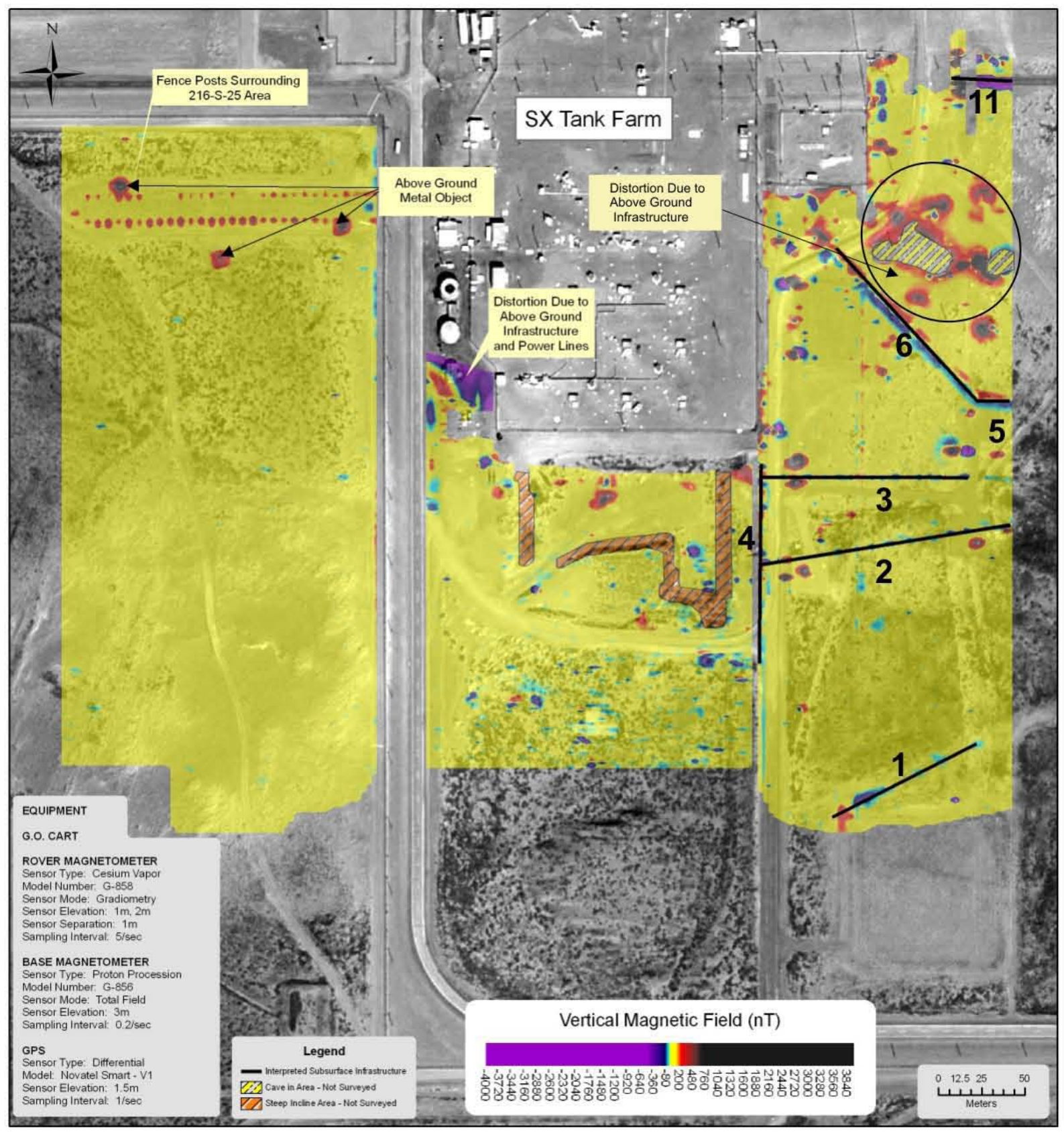


Figure ES-2. Electrical Conductivity from the Electromagnetic Induction at $10 \mathrm{KHz}$.

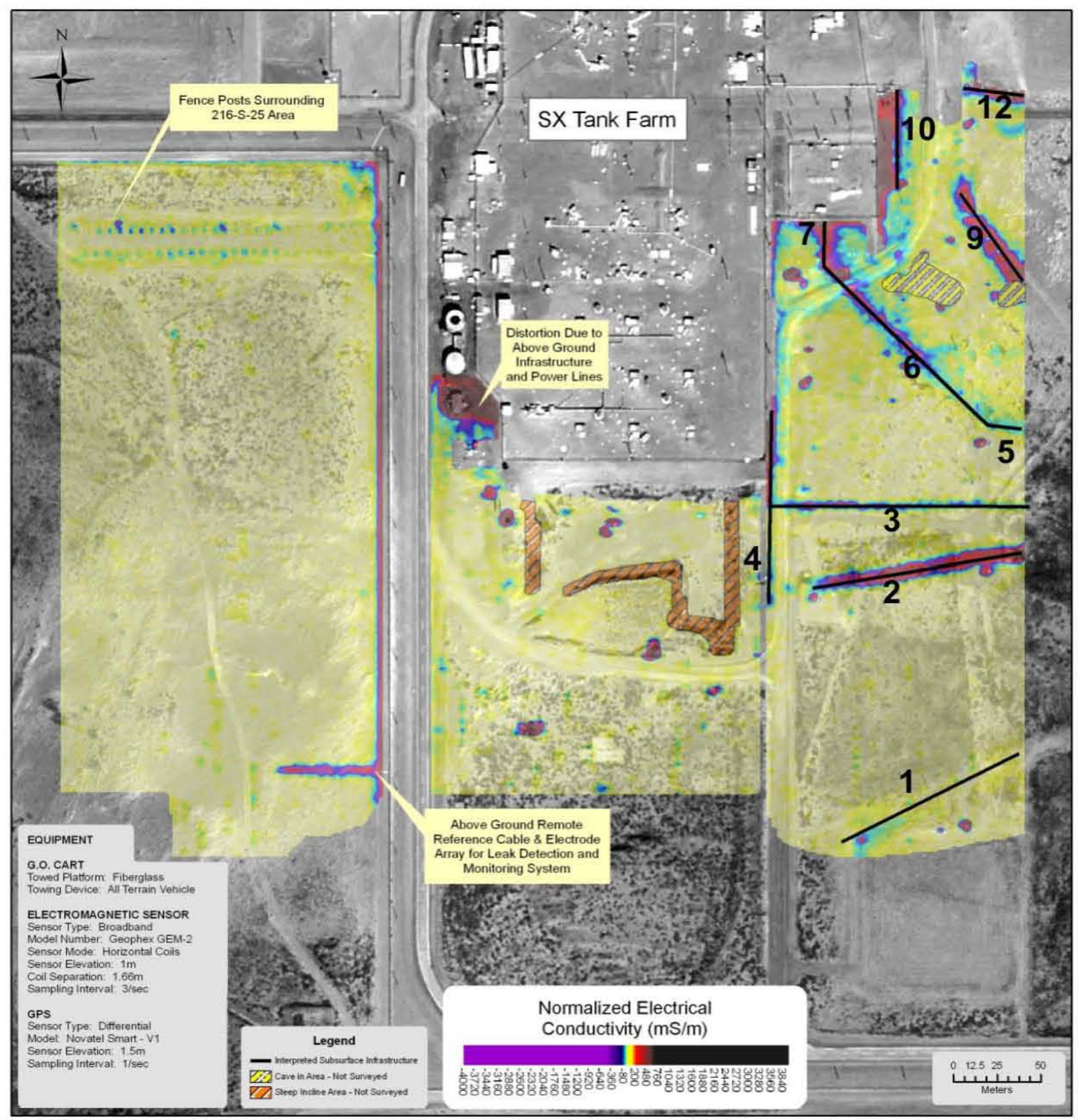

Figure ES-3 shows a compilation of interpretation features identified from the magnetic gradiometry and electromagnetic survey and an overlay of available Hanford Site infrastructure maps. The figure indicates agreement between the methods for the majority of features. Features that do not correlate between the electromagnetic and magnetic gradiometry surveys provide additional segregation of material properties that will be used to support resistivity data interpretation. All but one interpreted feature correlates with available infrastructure maps. The 
remaining feature (detailed as interpreted feature \#2) shows a strong pipeline response observed on both electromagnetic and magnetic gradiometry results in the area southeast of the SX tank farm as indicated on Figure ES-3. Towards the far northeast, the infrastructure maps show the existence of a subsurface pipeline; however, there is no associated electromagnetic or magnetic gradiometry response (indicated as "missing pipeline section?" on map). The Geophysical Operations Cart ${ }^{\text {Tx }}$ survey results suggest that the section of pipeline has been removed or the maps are incorrect.

Figure ES-3. Summary of Interpreted Features from G.O. Cart ${ }^{\mathrm{TM}}$ Survey.

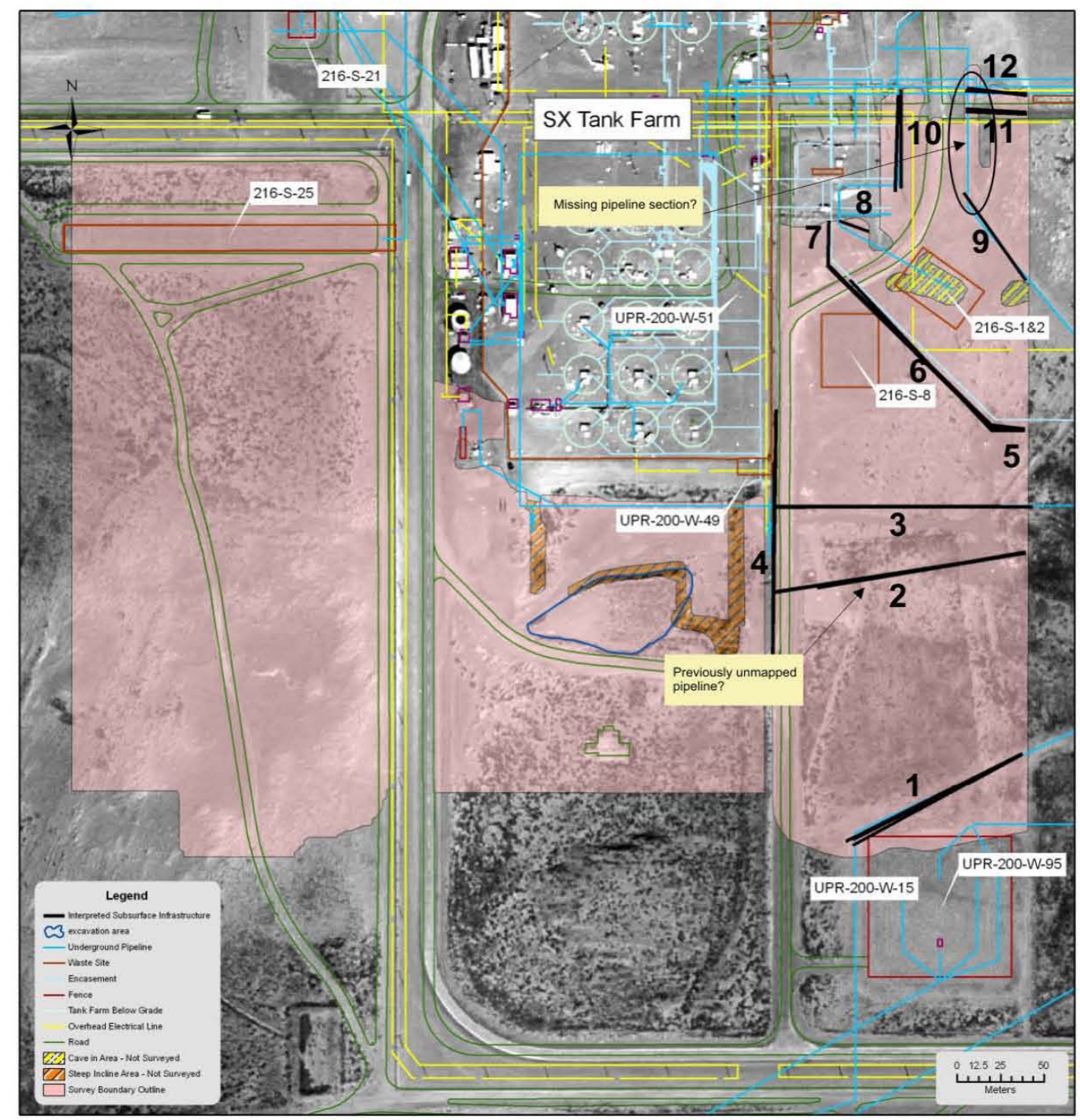

G.O. Cart $=$ Geophysical Operations Cart.

${ }^{\mathrm{TM}}$ Geophysical Operations Cart and G.O. Cart are trademarks of hydroGEOPHYSICS, Inc.

\footnotetext{
${ }^{\mathrm{TM}}$ Geophysical Operations Cart is a trademark of hydroGEOPHYSICS, Inc.
} 


\section{TABLE OF CONTENTS}

$1.0 \quad$ INTRODUCTION

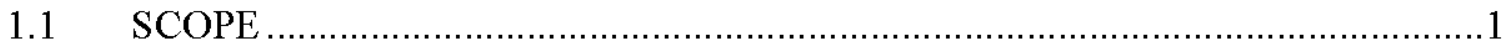

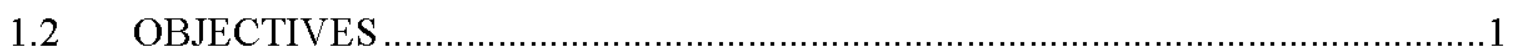

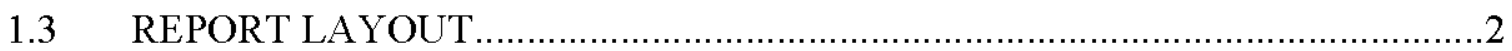

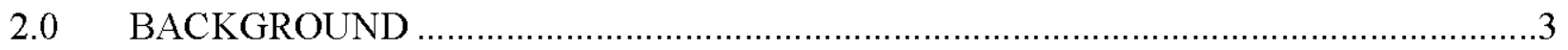

$3.0 \quad$ THEORY

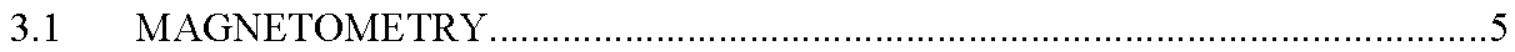

3.2 ELECTROMAGNETIC INDUCTION ………..............................................

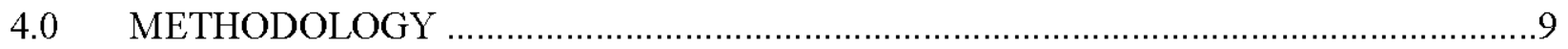

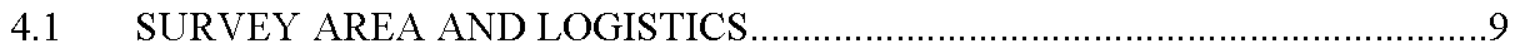

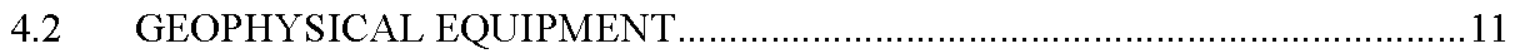

4.2.1 Geophysical Operations Cart ..........................................................11

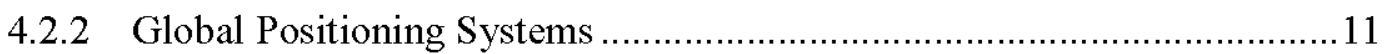

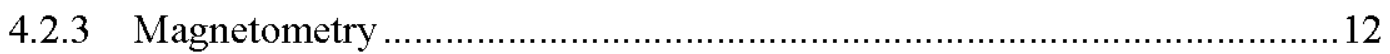

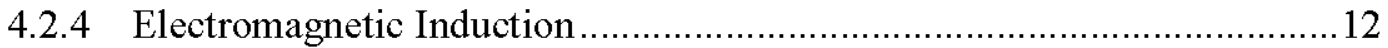

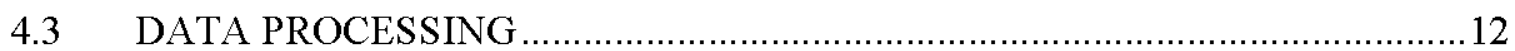

4.3.1 Downloading, Parsing, Quality Control - Onsite ……………...............12

4.3.2 Magnetics Processing and Plotting ……………....................................14

4.3.3 Electromagnetic Processing and Plotting.............................................20

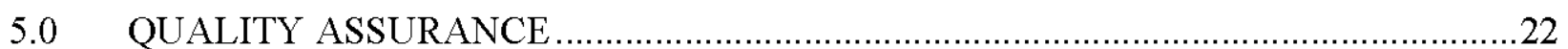

5.1 CALIBRATION AND MAINTENANCE OF EQUIPMENT AND

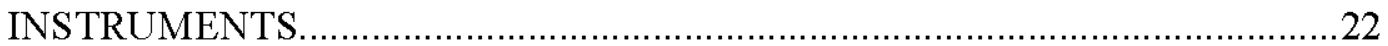

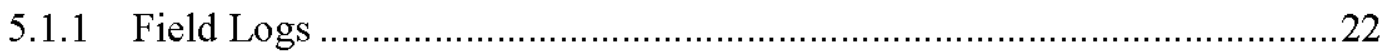

6.0 ANALYSIS, RESULTS AND INTERPRETATION

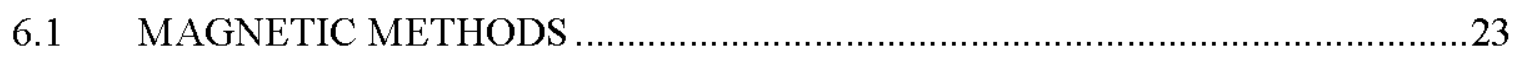

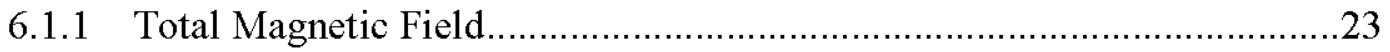

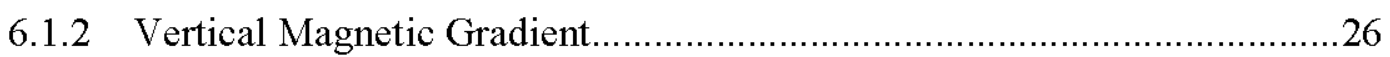

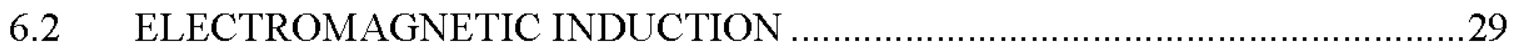

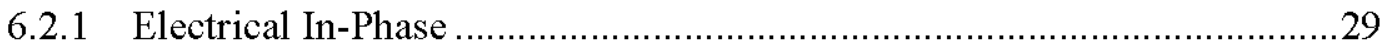

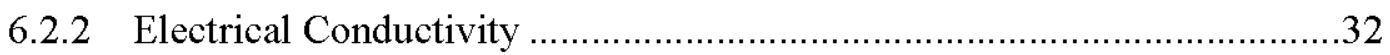

6.3 SUMMARY OF MAG AND EM FEATURES............................................... 


\section{LIST OF APPENDICES}

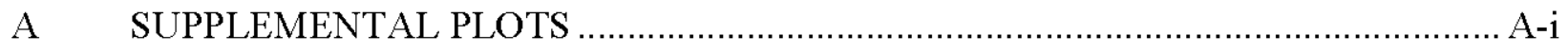

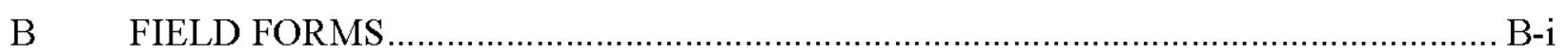

\section{LIST OF FIGURES}

2-1. S-SX Tank Farm and Surrounding Facilities ..........................................................

3-1. Magnetic Anomalies for a Sphere at (A) Mid Latitude, (B) Equator, and (C) Near

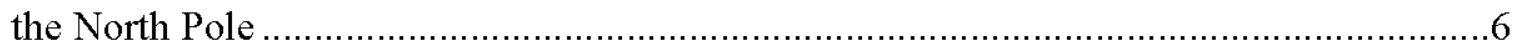

3-2. Depth Estimates for Magnetic Anomalies .................................................................... 7

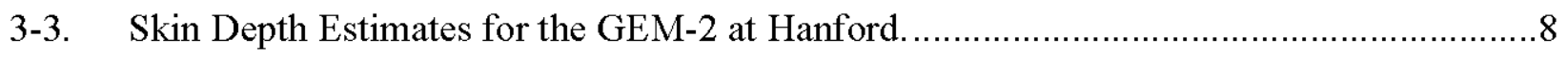

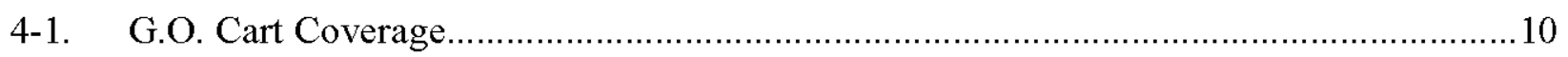

4-2. Geophysical Operations Cart Photo..................................................................... 11

4-3. Magnetic Base Station Data for the entire survey period. Blue regions indicate

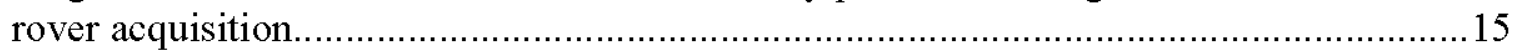

4-4. Magnetic Base Station Data for March 10, 2009......................................................16

4-5. Heading Error Associated with Magnetometer Readings for the Bottom Sensor. .............17

4-6. Heading Error Associated with Magnetometer Readings for the Top Sensor...................17

4-7. Smoothing Filter Used for Smoothing Magnetic Data. .............................................. 18

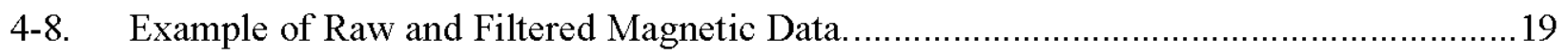

6-1. Total Magnetic Field Results with Interpreted Infrastructure.......................................24

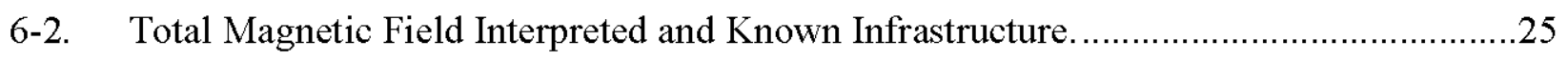

6-3. Vertical Magnetic Gradient Shown with Interpreted Infrastructure. ..............................27

6-4. Vertical Magnetic Gradient Interpreted and Known Infrastructure..................................28

6-5. Electrical In-Phase $(10 \mathrm{kHz})$ Results with Interpreted Features....................................30

6-6. Electrical In-Phase $(10 \mathrm{kHz})$ Interpreted and Known Features. ......................................

6-7. Electrical Conductivity $(10 \mathrm{kHz})$ Shown with Interpreted Infrastructure. ..........................33

6-8. Electrical Conductivity $(10 \mathrm{kHz})$ Interpreted Results Shown with Infrastructure

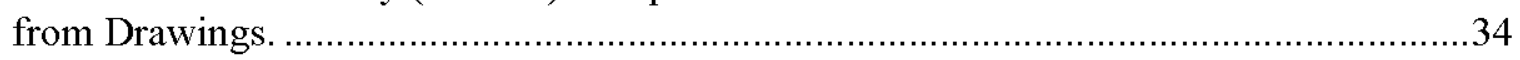

6-9. Summary of Interpreted Features from G.O.Cart ${ }^{\mathrm{TM}}$ Survey ...........................................

\section{LIST OF TABLES}

4-A. Magnetic Data File Names, Acquisition Dates, and Data Count....................................13

4-B. Electromagnetic Data File Names, Acquisition Dates, and Data Count............................14 
RPP-RPT-42512, Rev. 0

\section{LIST OF TERMS}

\section{Terms}

Conductivity. The ability of a material to transmit or conduct an electric impulse; reciprocal of resistivity.

Inversion. Inversion, or inverse modeling, attempts to reconstruct subsurface features from a given set of geophysical measurements, and to do so in a manner that the model response fits the observations according to some measure of error.

Resistance. The opposition of a material to current passing through it; received voltage normalized by transmitted current.

\section{Abbreviations and Acronyms}

Columbia Energy Columbia Energy \& Environmental Services, Inc.

EM

electromagnetic

G.O. $\operatorname{Cart}^{\mathrm{r} \mathrm{M}}$

Geophysical Operations Cart ${ }^{\mathrm{TM}}$

GPS

Global-Positioning System

HGI

hydroGEOPHYSICS, Inc.

MAG

magnetic gradiometry

WMA

waste management area

${ }^{\mathrm{rm}}$ G.O. Cart is a trademark of hydroGEOPHYSICS, Inc.

${ }^{\mathrm{rm}}$ Geophysical Operations Cart is a trademark of hydroGEOPHYSICS, Inc. 
RPP-RPT-42512, Rev. 0

\subsection{INTRODUCTION}

From February to March 2009, a preliminary geophysical study was completed for the waste management area (WMA) surrounding the 241-SX tank farm at the U.S. Department of Energy's Hanford Site in eastern Washington State. Columbia Energy \& Environmental Services, Inc. (Columbia Energy) of Richland, Washington, and hydroGEOPHYSICS, Inc. (HGI) of Tucson, Arizona, with support from Washington River Protection Solutions, conducted background geophysical surveys of the WMAs surrounding the SX tank farm located in the 200 West Area of the Hanford Site. The geophysical surveys consisted of electromagnetic (EM) induction and magnetic gradiometry (MAG) around the periphery of the tank farms.

This report will support a follow-on report documenting the results of a resistivity survey of the SX tank farm and surrounding areas. The purpose of this report is to document the findings of the EM and MAG survey of the areas surrounding the SX tank farm in an effort to identify the presence of buried infrastructure. This information in turn is to be used as an aid in the processing and interpretation of the resistivity results. A high concentration of buried infrastructure will influence the resistivity results and should be taken into consideration when making interpretations.

\subsection{SCOPE}

The scope of the geophysical surveying included data acquisition, processing, and visualization of EM induction and MAG for areas outside the SX tank farm fence lines to map buried infrastructure. Potential targets for the survey include buried pipelines, electrical conduits, and other grounded metallic objects that may interfere with direct-current electrical resistivity imaging. The survey was performed in accordance with RPP-PLAN-36704, Work Plan for Surface Geophysical Exploration of the SX Tank Farm and Surrounding Areas. The scope of this survey does not include the mapping of electrolytic targets that are a result of increased salt or moisture content from the direct disposal of liquid waste to the vadose zone. However, such targets will be documented if detected as part of this survey.

The data acquisition was conducted by attaching the EM induction and magnetic gradiometry instruments to a Geophysical Operations Cart $^{\mathrm{TM}}$ (G.O. Cart), which included an all-terrain vehicle and a fiberglass-towed trailer. The G.O. Cart was outfitted with a Global-Positioning System (GPS) for geo-referencing of data and to allow tracking of its location while traversing the area. Data coverage included a total of approximately 40 acres. Greater than $300,000 \mathrm{EM}$ and greater than one million magnetic data point locations were acquired. For each data point location, the gradiometry survey provided data for both a top and bottom sensor, while the EM survey provided in-phase and conductivity data.

\subsection{OBJECTIVES}

The main objective for this geophysical investigation was to detect and map the location of subsurface buried metallic infrastructure and debris. The subsurface metal may interfere with electrical resistivity measurements, which are being completed as the second phase of the surface

\footnotetext{
${ }^{\mathrm{r}}$ Geophysical Operations Cart and G.O. Cart are trademarks of hydroGEOPHYSICS, Inc.
} 
geophysical exploration scope for the SX tank farm and surrounding areas geophysical characterization. The results of the electrical resistivity survey will be presented in a separate report.

\subsection{REPORT LAYOUT}

This report is divided into seven main sections.

- Section 1.0, Introduction - describes the scope and objectives of the investigation.

- Section 2.0, Background - describes the setting of the SX tank farm and information regarding the metallic infrastructure in and around the tank farm.

- $\quad$ Section 3.0, Theory - briefly provides the theory behind EM induction and magnetic gradiometry.

- $\quad$ Section 4.0, Methodology - discusses the methodology and logistics of conducting the geophysical survey at the SX tank farm.

- Section 5.0, Quality Assurance - description of quality assurance practices.

- $\quad$ Section 6.0, Analysis, Results and Interpretation - presents the results from the surveying effort.

- Section 7.0, Conclusions - provides conclusions drawn from the results, interpretations, and subsequent assessment of results.

- $\quad$ Section 8.0, References - lists reference documents cited in the report.

- Appendix A, Supplemental Plots - large format plots and additional magnetic and electromagnetic plots.

- $\quad$ Appendix B, Field Forms - field observation forms, and calibration statements. 
RPP-RPT-42512, Rev. 0

\subsection{BACKGROUND}

The SX tank farm is one of 12 single-shell tank farms on the Hanford Site. The SX tank farm is located in the southern portion of the 200 West Area. There are a number of past-practice liquid discharge facilities (i.e., cribs and trenches) located mainly to the east and west of the SX tank farm and the $\mathrm{S}$ tank farm is located directly to the north. See Figure 2-1.

Facilities of interest for magnetic and EM investigation around the SX tank farm include the surrounding cribs, tile fields, and trenches that were accessible from the surface. The locations of the facilities are shown on Figure 2-1. 
Figure 2-1. S-SX Tank Farm and Surrounding Facilities.

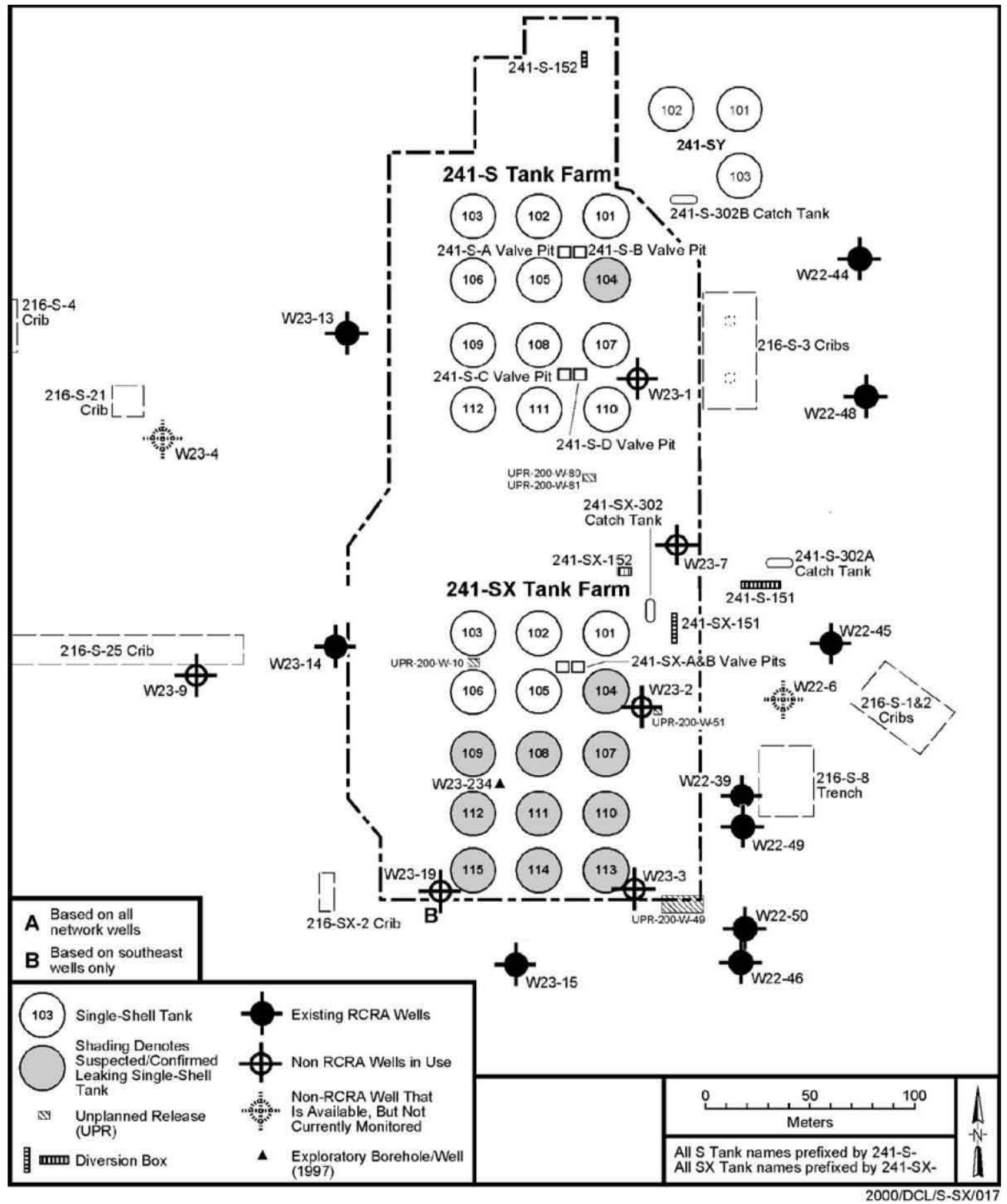

DOE/ORP-2008-01, 2008, RCRA Facility Investigation Report for Hanford Single-Shell Tank Waste

Management Areas Revision 0, U.S. Department of Energy, Office of River Protection, Richland, Washington. 
RPP-RPT-42512, Rev. 0

\subsection{THEORY}

This section provides summary level descriptions for the theory behind different geophysical tools and methods used in the assessment of SX farm.

\subsection{MAGNETOMETRY}

Magnetometry surveys measures the Earth's magnetic field (Telford, W.M., L.P. Geldart, and R.E. Sherriff, 1990, Applied Geophysics, Cambridge University Press, Cambridge, United Kingdom.) while, MAG is a measure of the gradient between two sensors located at different distances from the ground surface at a given location. The Earth's field is composed of three main parts:

- $\quad$ Main Field - internal to the Earth (i.e., from a source from within the Earth and varies slowly in time and space)

- $\quad$ Secondary Field - external to the Earth and varies rapidly in time

- $\quad$ Small Internal Fields - constant in time and space and are caused by local magnetic anomalies in the near-surface crust.

Measured, localized magnetic anomalies occur as a result of variation in magnetic susceptibility of materials. This is generally caused by the high magnetic susceptibility of magnetic minerals (i.e., magnetite, pyrrhotite, etc.) or buried steel, set in contrast to the low magnetic susceptibility of the background unconsolidated sediments. The average values for magnetic susceptibility are typically less than 1 for sedimentary formations and up to 20,000 for magnetite minerals.

From basic magnetic field theory (Grant and West, 1965) the magnetic field due either to a point (dipole) source, or a three-dimensional finite volume of magnetized material, decays in proportion to $r^{3}$ as the distance from the source increases, where $r$ is the separation between the source and the magnetometer. The gradient of the field, on the other hand, decays in proportion to $r^{4}$. By means of Fourier transform, it is possible to show that a signal proportional to $r^{4}$ has more power at higher spatial frequencies relative to a signal proportional to $r^{3}$ (the field itself). Consequently, the magnetic gradient signal due to a given three-dimensional source is more limited in spatial extent, making discrete near-surface bodies appearing more pronounced compared to background readings.

Schlinger (1990) showed the effects of a dipole source (i.e., a uniformly magnetized buried sphere on the geomagnetic field at several latitudes). Figure 3-1 shows where the anomaly is positioned at zero meters at a depth of two meters below ground surface with the measurement at two meters above the ground surface. The figure shows the response of both total magnetic field and vertical magnetic gradient. Both plotting methods are sufficient at discriminating bodies in the near surface, but the total field is only useful for determining deeply buried bodies.

The presentation of magnetic data is accomplished with a contour map, where the magnitude of the magnetic field or vertical magnetic gradient data is represented by isopleths. In general, the buried objects will appear as either a mono-polar or a dipolar anomalous response. For near-surface infrastructure mapping of steel objects, the values of the magnetic field can be 
several hundred to several thousand times higher than the background field. Linearly continuous anomalies observed along adjacently acquired data are interpreted as buried pipelines and singular anomalies that are not continuous are interpreted as discrete buried objects (tanks, drums, wells, or other metal that comprise the construction of tank farms).

Figure 3-1. Magnetic Anomalies for a Sphere at (A) Mid Latitude, (B) Equator, and (C) Near the North Pole.
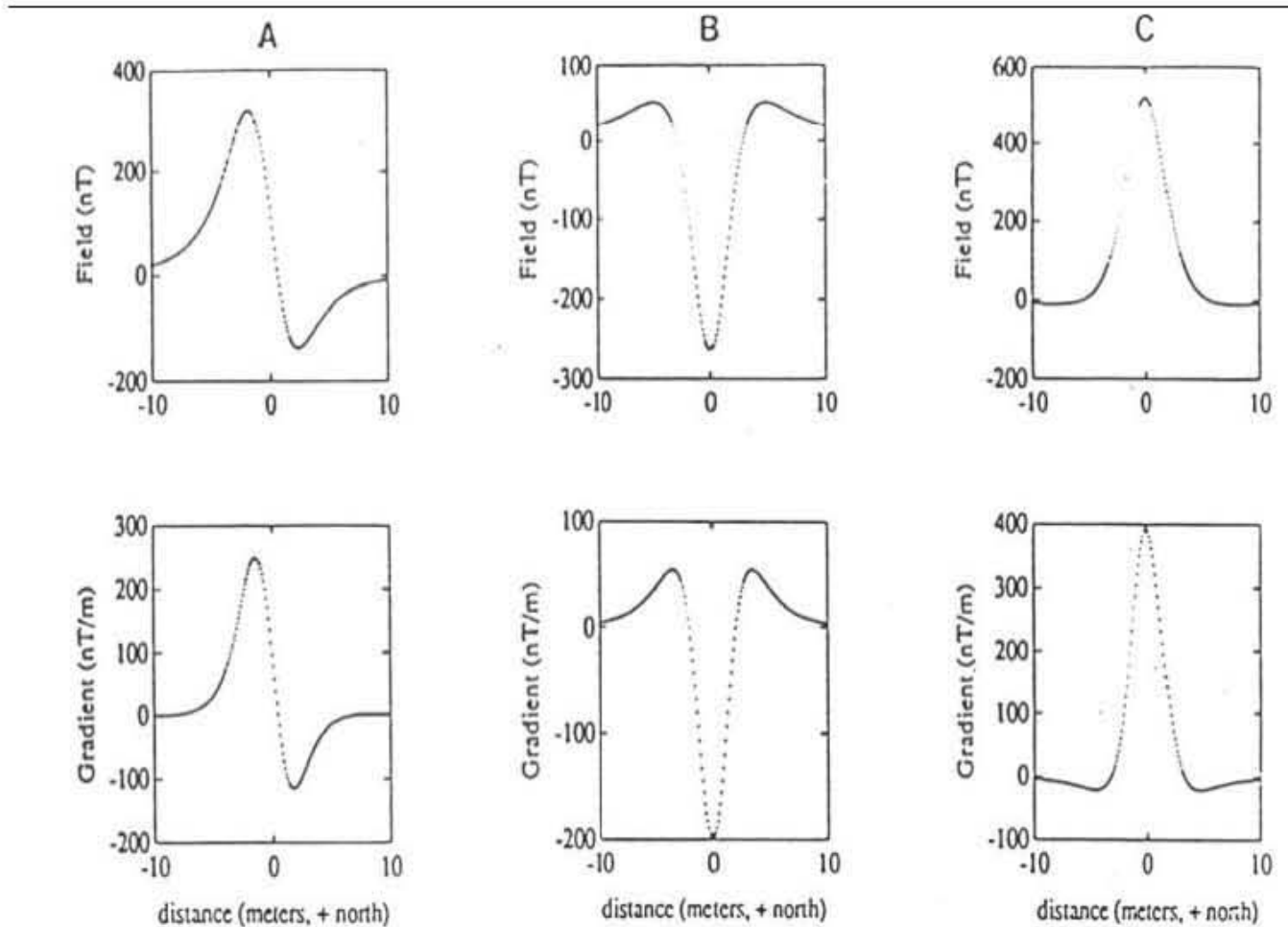

Source: Schlinger, C.M., 1990. Magnetometer and Gradiometer Surveys for Detection of Underground Storage Tanks. Bulletin of the Association of Engineering Geologists Vol. XXVII:37-50.

The magnetic field is measured with a magnetometer. Magnetometers permit rapid, non-contact surveys and were used outside the farm to locate buried ferrous objects and features. Portable one-person field units can be used virtually anywhere that is accessible. Field portable magnetometers may be single- or dual-sensor. Dual-sensor magnetometers are called gradiometers and measure gradient of the magnetic field; single-sensor magnetometers measure total field.

Magnetic surveys are typically completed with two separate magnetometers. The first magnetometer is used as a base station to record the Earth's primary field and the diumally changing secondary field. The second magnetometer is used as a rover to measure the spatial variation of the Earth's field. A residual magnetic field from local spatial variations is calculated by removing the temporal variation and, perhaps, the static value of the base station, from that of the rover.

The shortcoming with most magnetometers is that they only record the total magnetic field, $\mathrm{F}$, and not the separate components of the vector field. This shortcoming can make the 
interpretation of magnetic anomalies difficult. Furthermore, the magnetic intensity or anomalies are highly variable in shape and amplitude. They are almost always asymmetrical, sometimes appear complex even from simple sources, and usually portray the combined magnetic effects of several sources (Applications Manual for Portable Magnetometers [Breiner 1973]). There are simplified depth estimation techniques based on graphical evaluation of data using the half-width rule. In magnetic fields, it can be shown for simple forms that the depth to the center of a buried object is related to the half-width of the measured anomaly. The half-width is the horizontal distance between the principal maximum or minimum of the anomaly which is (assumed to be over the center of the source) and the point where the value is exactly one-half the maximum value. See Figure 3-2 adapted from Breiner. This rule is only valid for simple shaped forms such as a sphere, horizontal cylinder, vertical cylinder, and the edge of a narrow, nearly vertical dike.

\section{Figure 3-2. Depth Estimates for Magnetic Anomalies.}

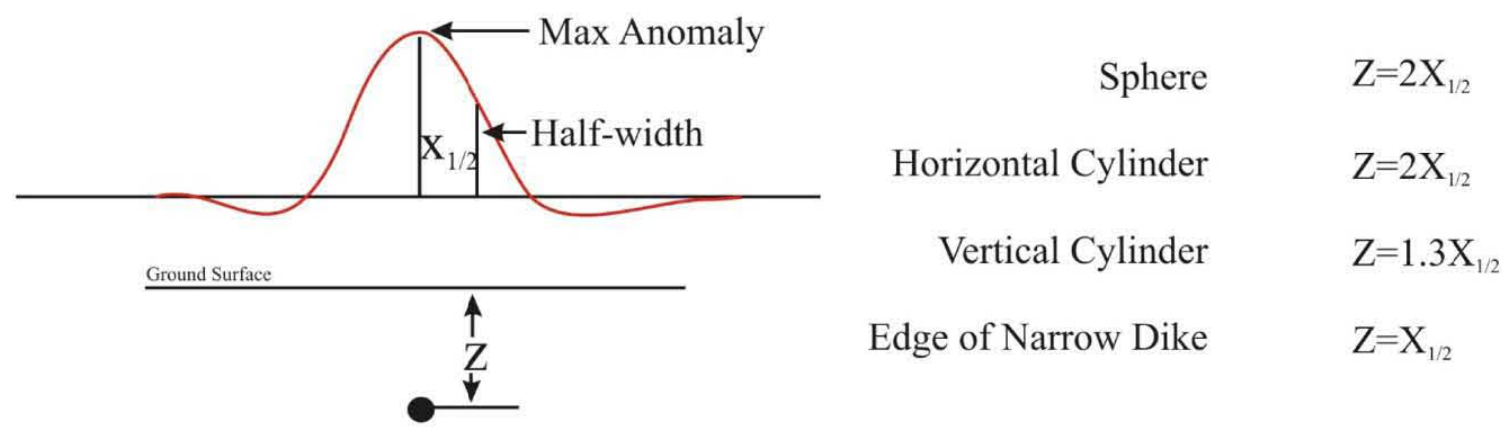

Source: Breiner, S., 1973. Applications Manual for Portable Magnetometers. Geometrics, Inc. San Jose, California.

\subsection{ELECTROMAGNETIC INDUCTION}

Earth materials have the capacity to transmit electrical currents over a wide range depending on the material property of electrical conductivity. Electrical conductivity is a function of soil type, porosity, saturation, and dissolved salts. EM induction identifies various earth materials by measuring their electrical characteristics and is used to identify buried infrastructure within the area where resistivity data are collected.

EM induction methods use a transmitting coil and a receiving coil. The transmitting coil induces eddy currents in the Earth, which themselves generate magnetic fields that are affected by the earth materials within the excited zone. The receiving coil intercepts the field resulting in an output voltage that is proportional to the conductivity within the area. Moving these coils results in variations in conductivity that can be interpreted to find buried features or objects.

The transmitting coil frequency and electrical conductivity of the host material primarily determine the depth of investigation for EM induction techniques. Referred to as skin depth in the literature (Applied Geophysics [Telford et al., 1990]), it generally describes the decay of the 
EM field through a conductive medium. Formally, the skin depth $(\delta)$ is defined as the distance through which the field decays to e-1 $(\sim 37 \%)$ of its original amplitude:

Skin Depth: $\delta=\sqrt{\frac{2}{(\pi f) \mu \sigma}}$

Where:

$$
\begin{array}{ll}
\sigma & =\text { electrical conductivity of the host material } \\
\mu & =\text { magnetic permeability } \\
\mathrm{f} & =\text { operating frequency of the instrument }
\end{array}
$$

Graphically, Won (1980) developed a nomogram, from which the skin depth may be determined from a given frequency. Figure 3-3 shows the nomogram and an example of skin depth for Hanford specific soils. For the $10 \mathrm{kHz}$ frequency, it is expected that the skin depth is approximately ten meters.

There are several advantages of using a broadband, multi-frequency EM sensor. Since conductivity and permeability of the host material cannot be manipulated, the skin depth can be changed by changing frequencies. In theory, scanning through a frequency window is equivalent to depth soundings, where the results from multiple frequencies can be presented to understand the layering of earth materials. However, in practice HGI has observed that a fixed object of high conductivity (such as a metal pipe) will appear in all frequencies, eliminating the possibility of depth-specific estimations for individual targets.

Figure 3-3. Skin Depth Estimates for the GEM-2 at Hanford..

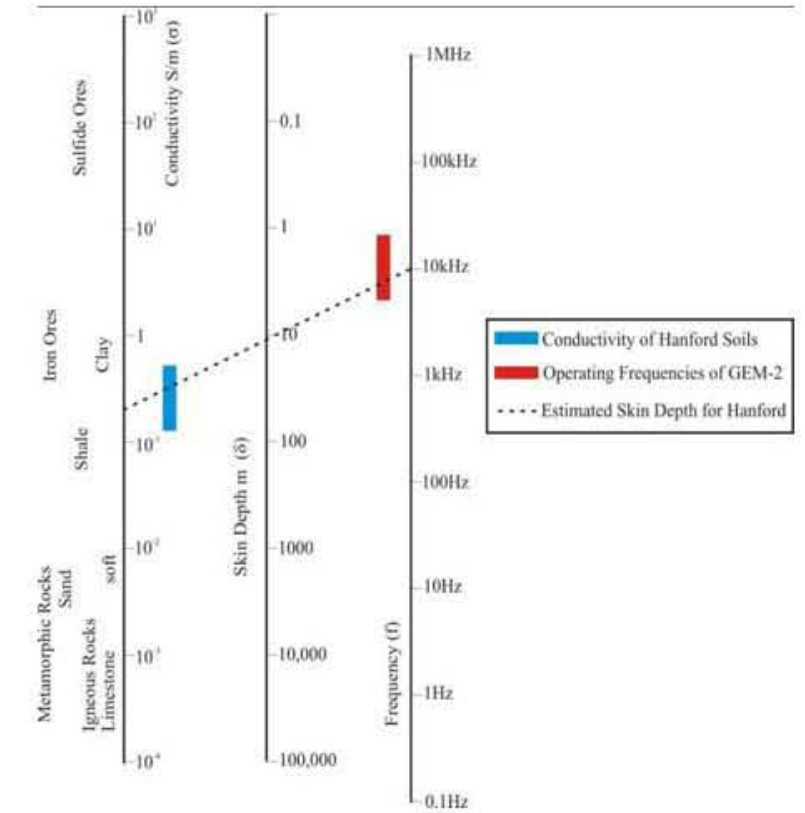

Adapted from: Won, I.J., 1980. A wideband electromagnetic exploration method Some theoretical and experimental results. Geophysics 45 (3):928-940. 
RPP-RPT-42512, Rev. 0

\subsection{METHODOLOGY}

\subsection{SURVEY AREA AND LOGISTICS}

This section describes the equipment and methodology used to collect, manage, and process geophysical data around the SX WMA. The basis for the survey coverage, equipment selection, methodology, data collection practices, functions and requirements and quality assurance guidelines are discussed in detail within RPP-PLAN-36704, Work Plan for Surface Geophysical Exploration of the SX Tank Farm and Surrounding Areas.

A summary of the survey coverage area can be viewed in Figure 4-1. For this figure, G.O. Cart survey coverage is shown in blue and daily coverage areas are shown as colored sections.

Data acquisition commenced on February 13, 2009, by establishing a stationary magnetic base station. The magnetic base station data were used to record variations in the magnetic field due to fluctuations in solar radiation. These daily variations, called diurnal noise, are removed from the magnetic field data acquired using the roving magnetometer attached to the G.O. Cart.

A combination of a two sensor Geometrics G-858G rover cesium-vapor gradiometer and a single sensor G-856 proton-procession base magnetometer provided magnetic data for this Surface Geophysical Exploration project because each instrument satisfied job-specific requirements listed in RPP-PLAN-36704. The two instruments are commercially available and were designed to be used together to provide diurnally corrected total field (rover top sensor data normalized to base station data) information. The selected equipment has been used on all prior Surface Geophysical Exploration style surveys (T complex; B, BX, and BY farms; and BC cribs) within the Hanford Site and is considered industry-standard equipment.

The gradiometer is easily adapted for use on the custom fabricated non-magnetic G.O. Cart (HGI) which can be viewed in Figure 4-2. The separation between the magnetic sensors and the data acquisition and storage console is increased using standard extension cables to cover the span between the trailer and the ATV. This separation is important in reducing the disruption to the magnetic field caused by the metal in the all-terrain vehicle. The gradiometer console contains a serial input and necessary firmware that is used to interface with and store GPS data. Interchangeable $12 \mathrm{~V} \mathrm{DC}$ gel cell batteries supply power to the gradiometer console located on the all-terrain vehicle just behind the operator. The gradiometer and base magnetometer operate independently, but the internal clocks for each instrument are synchronized before surveying. Both instruments record a time stamp for each data point so that post processing of diurnal corrections can be completed. 
RPP-RPT-42512, Rev. 0

Figure 4-1. G.O. Cart Coverage.

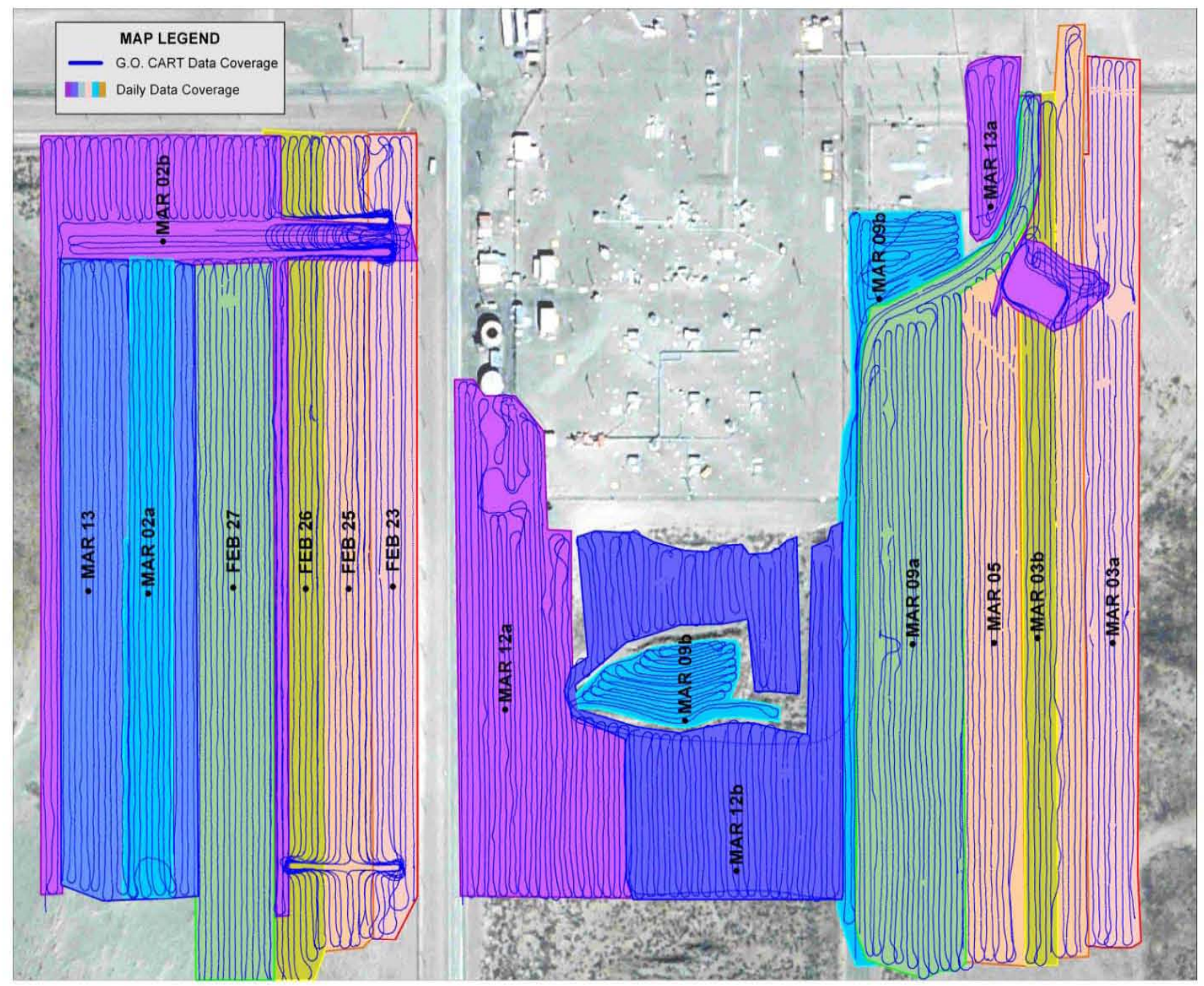




\section{Figure 4-2. Geophysical Operations Cart Photo.}

\section{Geophysical Operations Cart}

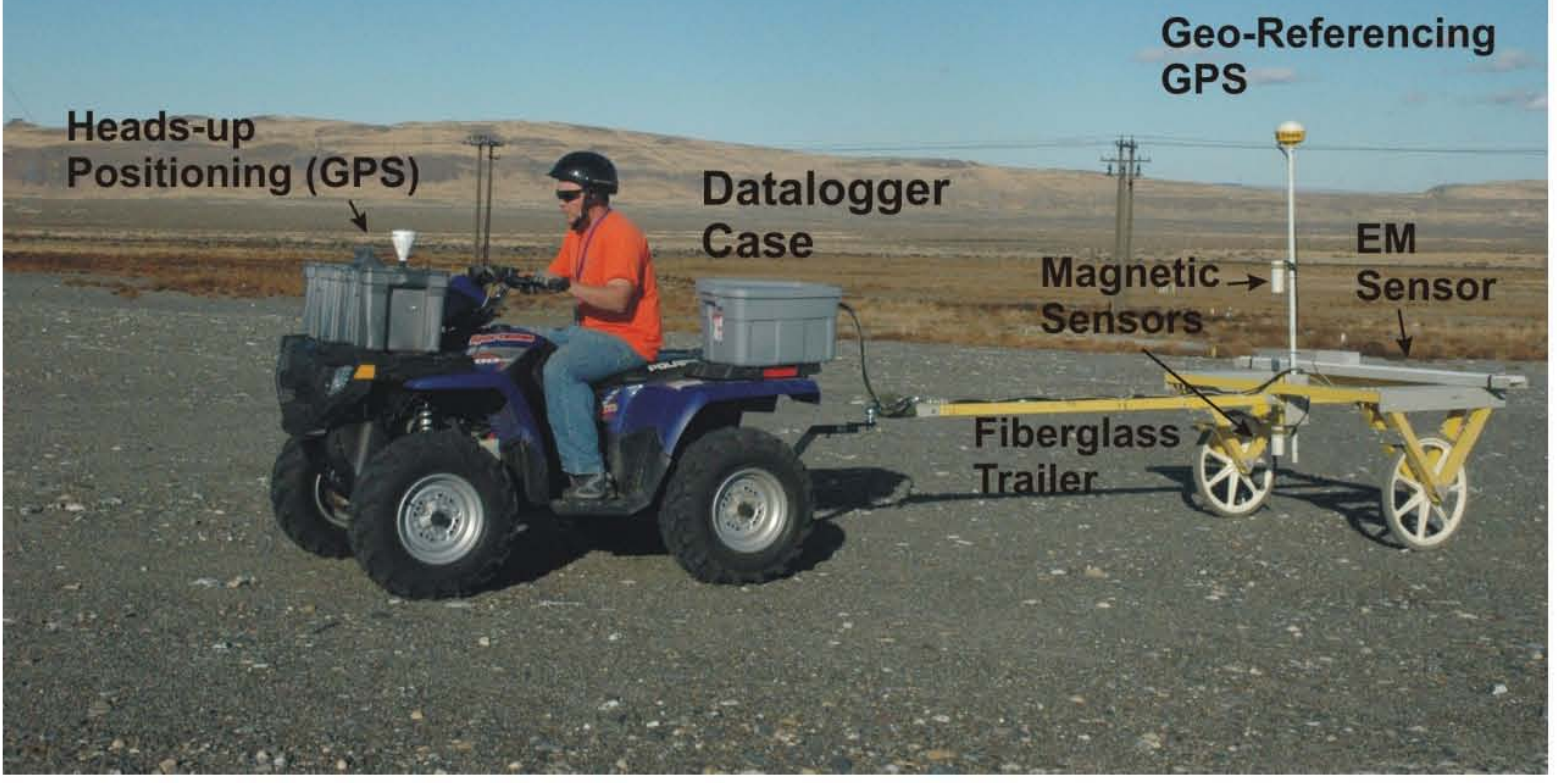

\subsection{GEOPHYSICAL EQUIPMENT}

Five different geophysical or surveying equipment types were deployed at the SX WMA. The different geophysical instruments are described in the following sections

\subsubsection{Geophysical Operations Cart}

The complexity of site characterization required information about multiple physical properties that were combined to enhance characterization efforts. Recent technological advances in mobile computing and geophysical instrumentation have greatly improved surveying. The G.O. Cart provides the ability to simultaneously deploy multiple survey instruments.

\subsubsection{Global Positioning Systems}

A NovAte ${ }^{\circledR}$ GPS was used to establish the physical location of magnetic and EM data. The accuracy of the data point position is a function of the G.O. Cart speed and accuracy of the GPS. The G.O. Cart speed was held at five miles per hour or less in order to improve data density and positional accuracy. Therefore, the estimated accuracy of the data point position is within 3.3 feet ( 1 meter) for this survey.

\footnotetext{
NovAtel is a registered trademark of NovAtel Inc.
} 


\subsubsection{Magnetometry}

Two magnetometers by Geometrics, Inc. were used to monitor variations within the Earth's magnetic field. A single sensor model G- 856 proton procession magnetometer was used as a stationary base station and a model G- $858 \mathrm{G}$ cesium vapor magnetometer was used as a roving magnetic gradiometer. The G-858G was configured with two sensors oriented vertically, spaced one meter apart with the lowest sensor approximately 0.5 meters from the ground surface. This configuration allowed for the calculation of the vertical gradient.

\subsubsection{Electromagnetic Induction}

EM induction data were collected using a Geophex, Ltd. GEM ${ }^{\circledR}-2$ instrument. The GEM-2 is a broadband multi-frequency meter (from $300 \mathrm{~Hz}$ to $96 \mathrm{kHz}$ ) with bi-static transmitter and receiver coils. The coils have a separation of 1.6 meters. Based on survey design, three frequencies were selected for the survey: $5.05 \mathrm{kHz}, 9.99 \mathrm{kHz}$ and $20.01 \mathrm{kHz}$, however, only the $9.99 \mathrm{kHz}$ frequency was processed and interpreted for this report. Previous experience has shown little benefit in the processing and interpretation of multiple frequencies for the detection and mapping of infrastructure. HGI collected both in-phase and quadrature data for the EM signal. Typically, the in-phase data relates to magnetic susceptibility, and quadrature data relates to electrical conductivity. Each are a function of signal frequency, vertical distance of the coils to the ground, coil orientation (horizontal or vertical), and coil separation. The in-phase and quadrature data were subjected to an inversion algorithm provided by Geophex, Ltd as part of the instrument download software. The inversion algorithm converted the measured quadrature data to electrical conductivity.

\subsection{DATA PROCESSING}

\subsubsection{Downloading, Parsing, Quality Control - Onsite}

The rover and base magnetic data were downloaded to a field laptop computer using Geometrics, Inc. MagMap2000 software. The data were saved in binary format, with the instrument type, date stamp, and location as part of the naming structure. Table 4-1 lists the data files for the magnetic data and Table 4-2 lists the files for the EM data. The G.O. Cart survey was completed using a series of small grids that were designed to accommodate site logistics. A preliminary assessment of each survey grid was conducted onsite each day. If unacceptable data are detected, then data for the affected area is recollected.

\footnotetext{
${ }^{\circledR}$ GEM is a registered trademark by Geophex.
} 
RPP-RPT-42512, Rev. 0

Table 4-A. Magnetic Data File Names, Acquisition Dates, and Data Count. (2 Sheets)

\begin{tabular}{|c|c|c|c|}
\hline File Record & File Name & Date & Point Count \\
\hline 1 & $858.02 .23 .2009 \mathrm{a}$ & $23-\mathrm{Feb}-2009$ & 73,159 \\
\hline 2 & $858.02 .25 .2009 \mathrm{~b}$ & $25-\mathrm{Feb}-2009$ & 80,728 \\
\hline 3 & $858.02 .26 .2009 \mathrm{a}$ & $26-\mathrm{Feb}-2009$ & 71,319 \\
\hline 4 & $858.02 .27 .2009 \mathrm{a}$ & $27-\mathrm{Feb}-2009$ & 73,598 \\
\hline 5 & $858.03 .02 .2009 \mathrm{a}$ & 02-Mar-2009 & 72,708 \\
\hline 6 & $858.03 .02 .2009 \mathrm{~b}$ & 02-Mar-2009 & 61,959 \\
\hline 7 & $858.03 .03 .2009 \mathrm{a}$ & 03-Mar-2009 & 77,149 \\
\hline 8 & $858.03 .03 .2009 \mathrm{~b}$ & 03-Mar-2009 & 76,758 \\
\hline 9 & $858.03 .05 .2009 \mathrm{a}$ & 05-Mar-2009 & 70,390 \\
\hline 10 & $858.03 .09 .2009 \mathrm{a}$ & 09-Mar-2009 & 79,520 \\
\hline 11 & $858.03 .09 .2009 \mathrm{~b}$ & 09-Mar-2009 & 47,950 \\
\hline 12 & $858.03 .11 .2009 \mathrm{a}$ & 11-Mar-2009 & 57,029 \\
\hline 13 & $858.03 .12 .2009 \mathrm{a}$ & $12-$ Mar-2009 & 69,950 \\
\hline 14 & $858.03 .12 .2009 \mathrm{~b}$ & 12-Mar-2009 & 68,339 \\
\hline 15 & $858.03 .13 .2009 \mathrm{a}$ & 13-Mar-2009 & 40,869 \\
\hline 16 & $858.03 .13 .2009 \mathrm{~b}$ & 13-Mar-2009 & 55,689 \\
\hline TOTAL & N/A & N/A & $1,077,114$ \\
\hline & & & \\
\hline
\end{tabular}

Onsite quality control included plotting the data point GPS locations onto the working SX WMA base map and verifying the location through visual observation. The plotting ensured that spatial coverage for the day met expectations, and off-normal situations (e.g., full data logger or dead battery) did not result in the loss of data. All binary files were uploaded daily for processing and evaluation of data quality statistics (i.e., low noise, sufficient data density, low drop-out rate). Onsite quality control also included plotting the base station magnetic field versus time to observe the diurnal changes in the base station data. 
RPP-RPT-42512, Rev. 0

Table 4-B. Electromagnetic Data File Names, Acquisition Dates, and Data Count. (2 Sheets)

\begin{tabular}{|c|c|c|c|}
\hline File Record & File Name & Date & Point Count \\
\hline 1 & Em.02.23.2009a & 23 -Feb-09 & 22,198 \\
\hline 2 & Em.02.24.2009b & $24-F e b-09$ & 19,067 \\
\hline 3 & Em.02.26.2009a & $26-$ Feb-09 & 21,448 \\
\hline 4 & Em.02.27.2009a & $27-$ Feb-09 & 21,917 \\
\hline 5 & Em.03.02.2009a & 02-Mar-09 & 22,009 \\
\hline 6 & Em.03.02.2009b & 02-Mar-09 & 18,726 \\
\hline 7 & Em.03.03.2009a & 03-Mar-09 & 23,243 \\
\hline 8 & Em.03.03.2009b & 03-Mar-09 & 23,126 \\
\hline 9 & Em.03.05.2009a & 05-Mar-09 & 21,163 \\
\hline 10 & Em.03.09.2009a & 09-Mar-09 & 23,932 \\
\hline 11 & Em.03.09.2009b & 09-Mar-09 & 14,374 \\
\hline 12 & Em.03.11.2009a & $11-$ Mar-09 & 17,097 \\
\hline 13 & Em.03.12.2009a & $12-$ Mar-09 & 20,962 \\
\hline 14 & Em.03.12.2009b & $12-$ Mar-09 & 20,504 \\
\hline 15 & Em.03.13.2009a & 13-Mar-09 & 12,294 \\
\hline 16 & Em.03.13.2009b & 13-Mar-09 & 16,710 \\
\hline TOTAL & N/A & N/A & 318,770 \\
\hline
\end{tabular}

\subsubsection{Magnetics Processing and Plotting}

The SX farm magnetic data processing included the following steps:

1. Removal of diurnal fluctuations was completed by subtracting the coincident base station data (G856 proton procession magnetometer) from the roving G.O. Cart gradiometer data (G858 cesium vapor gradiometer) using the Geometrics, Inc. supplied MagMap2000 software.

2. Coordinate conversion from a Universal Transverse Mercator to WA State Plane (meters) was completed using Corpscon, V.6 Software (U.S. Army Corps of Engineers).

3. Removing data spikes from the individual data files, using Microsoft Excel $^{\circledR}$.

4. Correcting data for variations in heading to reduce the effect of preferential alignment of the magnetic sensors with respect to the Earth's magnetic field, using Microsoft Excel.

5. Day-to-day normalization was performed to account for the day-to-day drift in the data using the daily calibration line as the normalization criteria.

\footnotetext{
${ }^{\circledR}$ Excel is a registered trademark of the Microsoft Corporation.
} 
6. Applying a 24-point smoothing filter to reduce high frequency chatter or noise, using Microsoft Excel.

7. Assembling the master table from the individual data files listed in Table 4-1, using Golden Software, Inc. Surfer ${ }^{\circledR}$ V.8 software.

8. Visualization of results using Surfer V.8 software.

4.3.2.1 Diurnal Correction. After downloading the data, the MagMap2000 software was used to make diurnal corrections. The diurnal correction was applied by subtracting the coincident time readings of the base station from the rover magnetic data. Subtracting the diurnal field from the total field resulted in a relative magnetic field for both the upper and lower magnetic sensors. Figure 4-3 shows the measured diurnal magnetic field for the duration of the survey. While, Figure 4-4 shows an example of the diurnal field for a single day, March 10, 2009.

Figure 4-3. Magnetic Base Station Data for the entire survey period. Blue regions indicate rover acquisition.

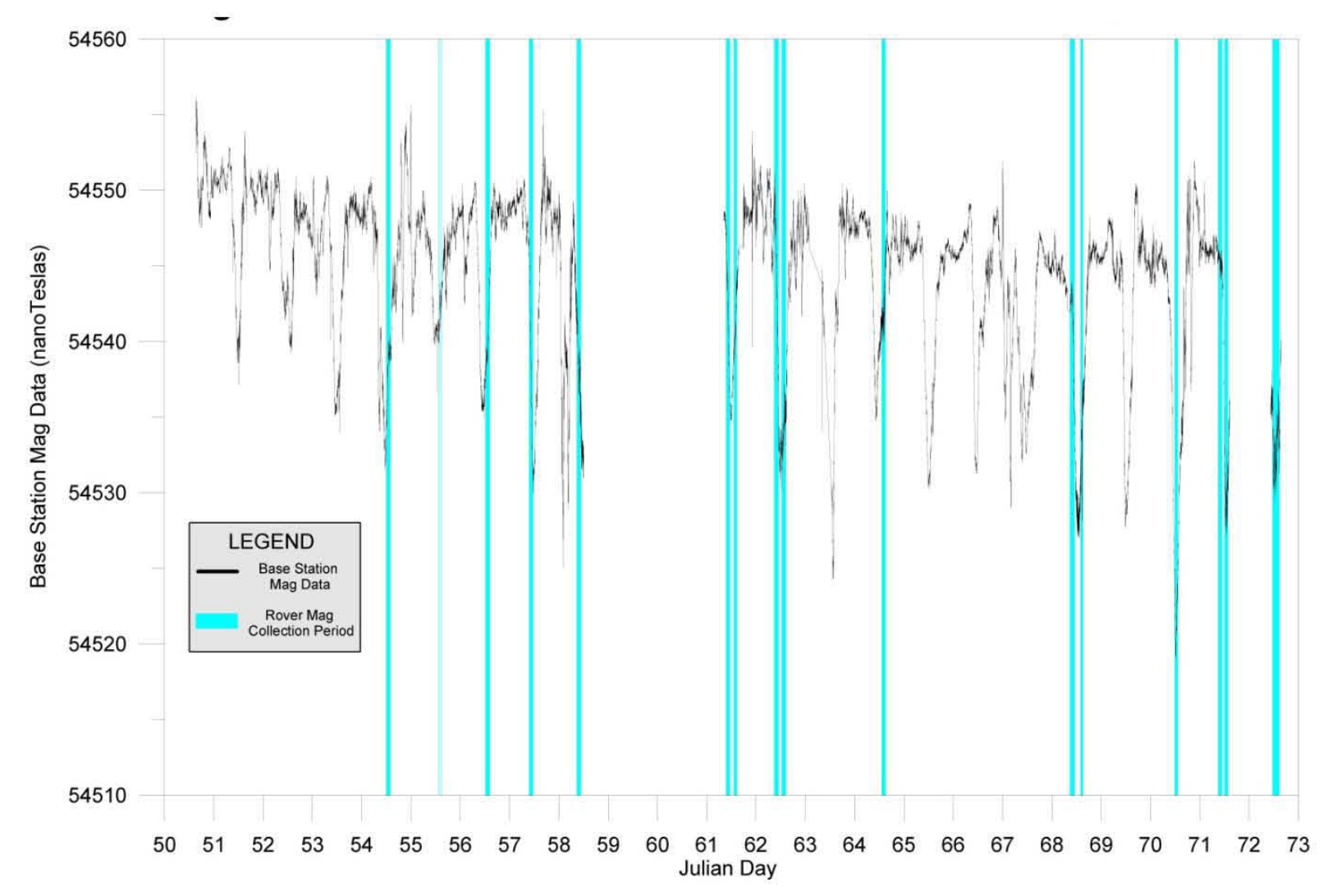

${ }^{\circledR}$ Surfer is a registered trademark of Golden Software, Inc. 
RPP-RPT-42512, Rev. 0

Figure 4-4. Magnetic Base Station Data for March 10, 2009

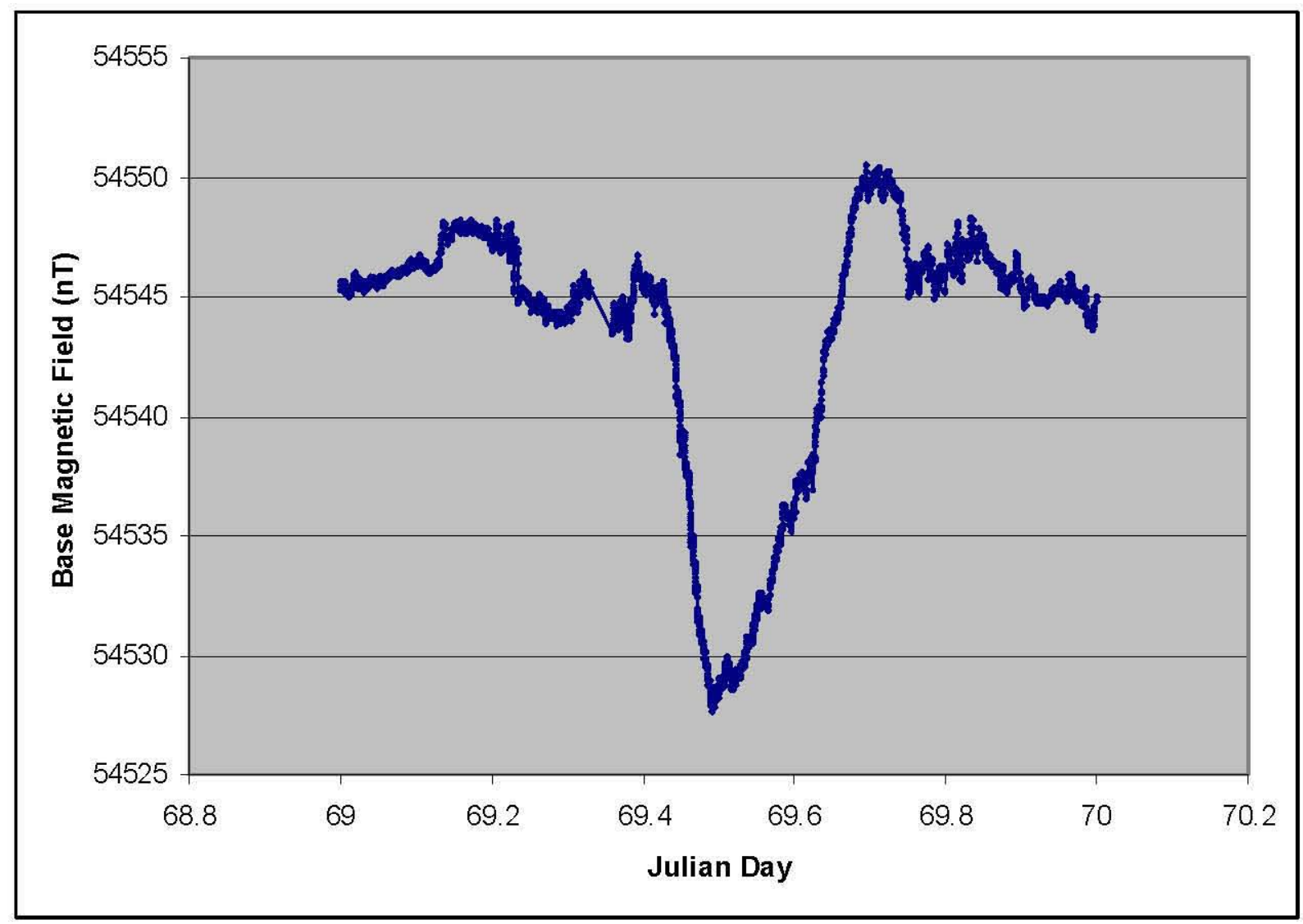

4.3.2.2 Coordinate Conversion. After diurnal corrections to the data, the GPS coordinate data are converted from a Universal Transverse Mercator to State Plane coordinate system using the U.S. Army Corps of Engineers Corpscon V.6 Software. GPS data were recorded every second and magnetic data were recorded five times per second, therefore the resulting GPS coordinate point for each magnetic reading was linearly interpolated within the magnetometers data acquisition system.

4.3.2.3 Spike Removal. After assembling the master table, erroneous large magnitude data spikes are removed. The total field magnetic data were typically around 54,000 nanoTeslas before diurnal corrections and ranged between $-1,500$ and 1,500 after diurnal corrections depending on items buried in the ground. A typical data spike had a value outside the range of $-2,000$ to 2,000 nanoTeslas.

4.3.2.4 Heading Correction. An attempt to correct for the heading error was completed, however, no correction can fully compensate for this complex field distortion. Heading error in the magnetic data results from the preferential alignment of the magnetic sensors with the Earth's magnetic field. Breiner (1973) discusses the heading error problem more thoroughly. Heading errors cause anomalous readings unrelated to any response from buried metallic debris. The 
error associated with heading was calculated from the magnetic data collected in eight distinct directions. Data were collected every 45 degrees from a northerly heading. A curve was fit for the direction of travel versus field strength for each sensor as shown in Figures 4-5 and 4-6, which was subtracted from the data.

Figure 4-5. Heading Error Associated with Magnetometer Readings for the Bottom Sensor.

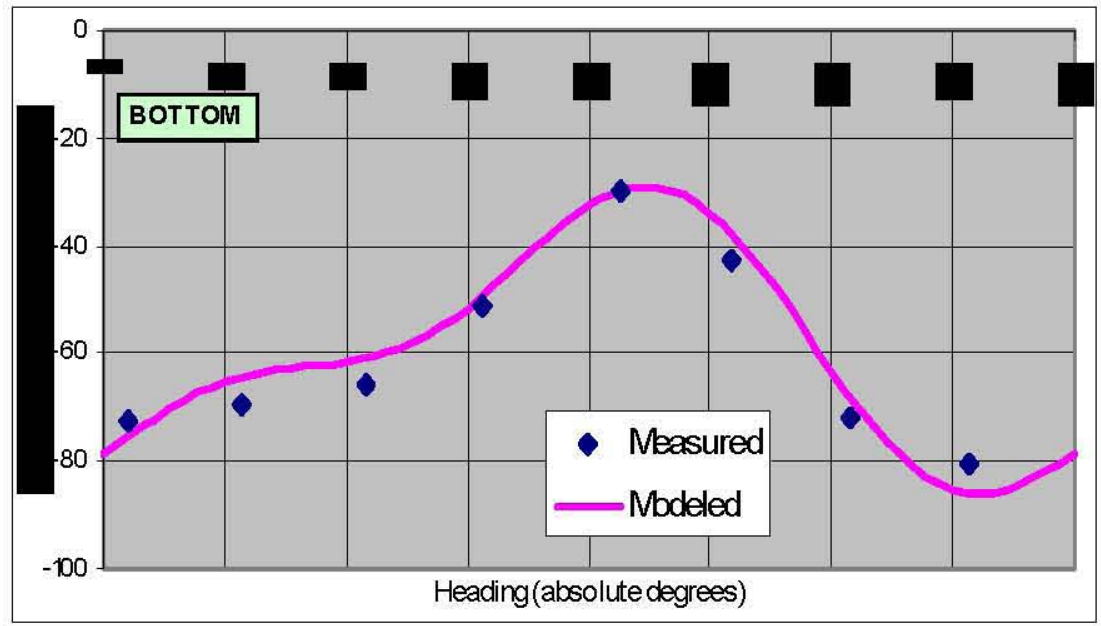

Figure 4-6. Heading Error Associated with Magnetometer Readings for the Top Sensor.

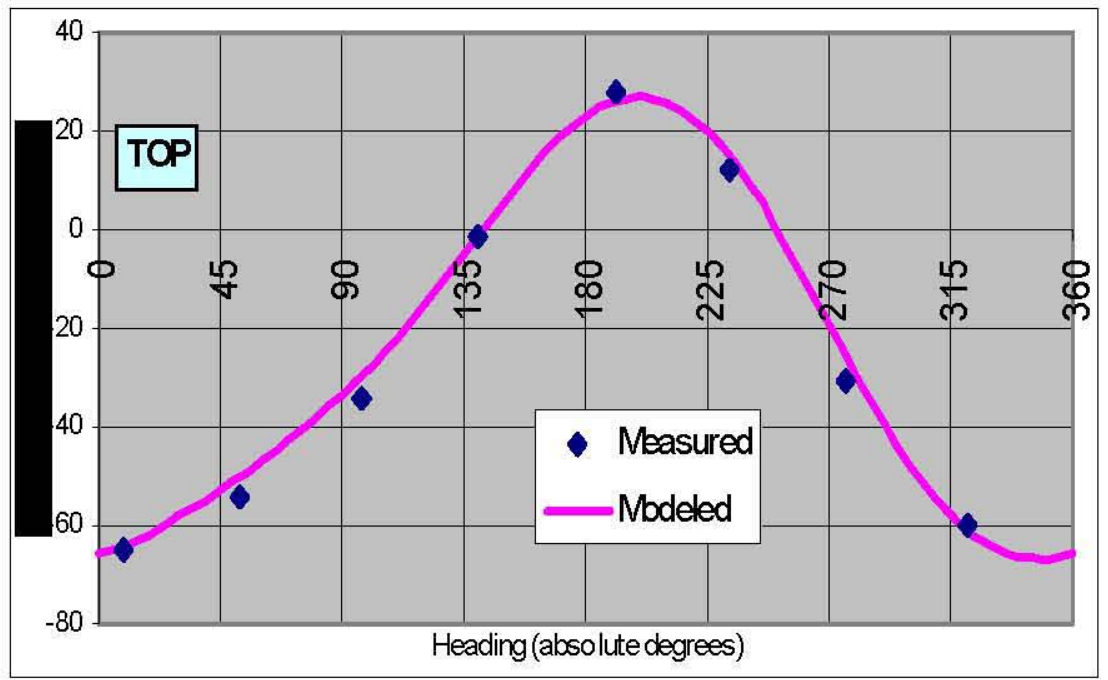

4.3.2.5 Day-to-day normalization. After adjustment for heading correction, each subsequent data set was normalized to the first data set acquired as part of this investigation. Curve 
matching for the calibration line, both upper and lower sensors, was completed in order to establish the normalization values for each subsequent data set. Once the normalization coefficient was determined for a given data set it was subtracted from all data points for that day. This process accounts for instrument drift throughout the survey.

4.3.2.6 Data smoothing. The last step in the processing regime involves smoothing the data to reduce high frequency noise. A 24-point smoothing filter was applied to each day separately to avoid overlap between days. Figure 4-7 shows a graph of the smoothing filter along with the associated coefficients. Figure 4-8 shows an example of raw data alongside the filtered data for the same time period.

Figure 4-7. Smoothing Filter Used for Smoothing Magnetic Data.

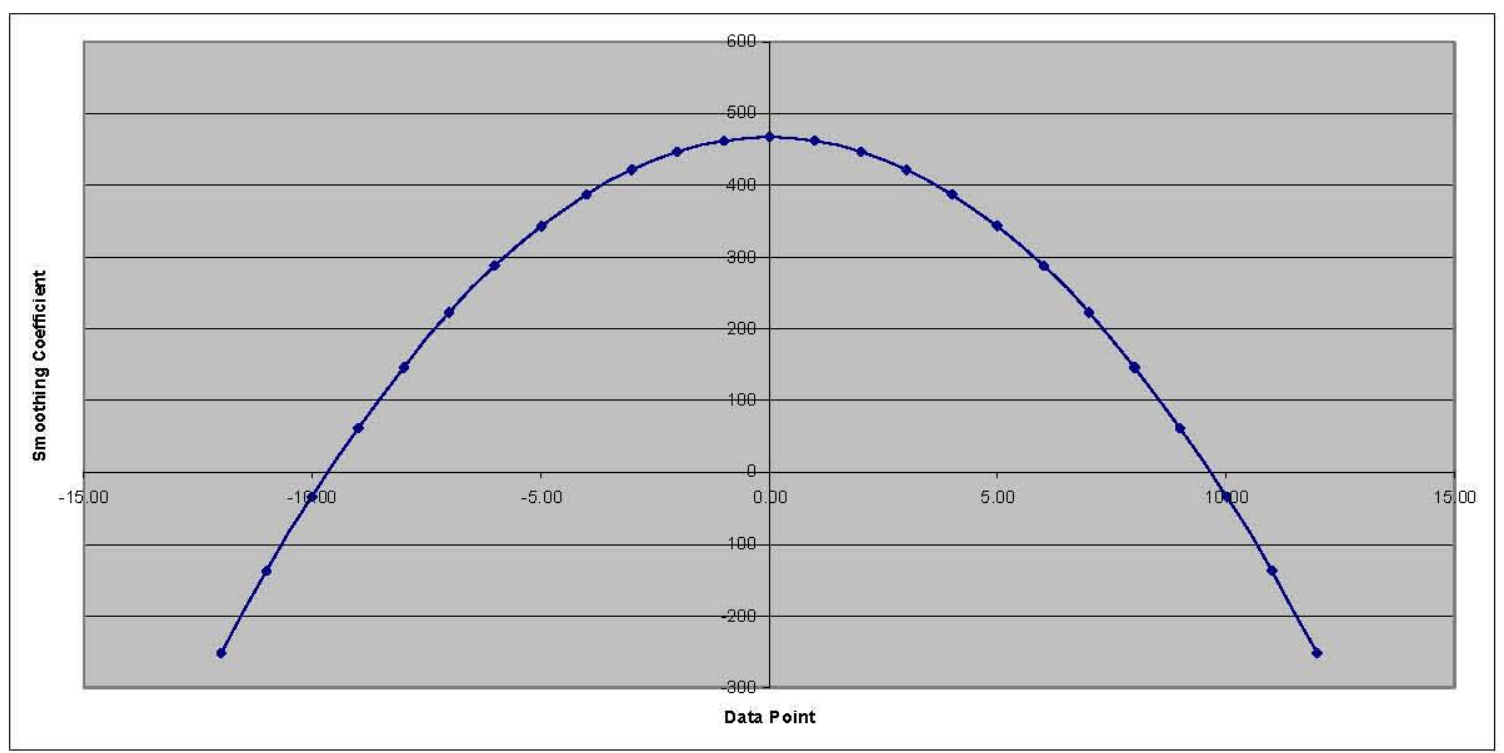


Figure 4-8. Example of Raw and Filtered Magnetic Data.

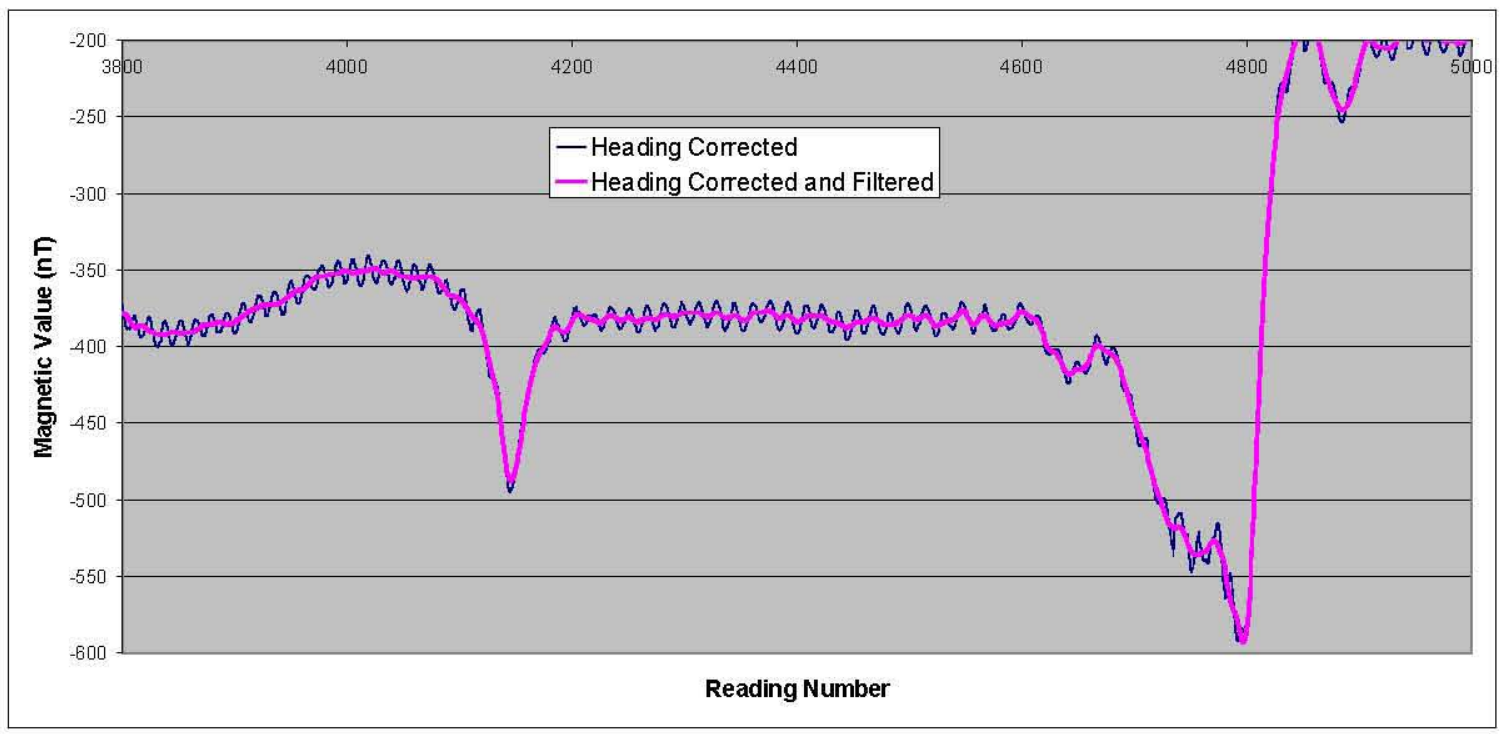

4.3.2.7 International Geomagnetic Reference Field Correction. It should be noted that the International Geomagnetic Reference Field was not subtracted from the magnetic data. The International Geomagnetic Reference Field allows the removal of large scale trends present in magnetic data that covers large areas. The survey coverage area for this project was small enough that an International Geomagnetic Reference Field correction was not necessary.

4.3.2.8 Assembling Master Table. After the processing steps are completed, the data from the individual survey files are combined within a single Surfer V.8 Software datasheet.

4.3.2.9 Data Plotting. The files were gridded in Surfer V.8 Software using a spatial interpolation algorithm (kriging or triangulation). The gridding and interpolation allowed a contour plot of data to be placed over the SX farm base map and interpretation of linear or discrete objects. Digital infrastructure maps for the SX farm area were developed from existing drawings for subsurface and above ground infrastructure. The digital map files are considered reference sources only and should not be considered as a direct representation of subsurface conditions. The infrastructure from the provided drawings and field observations are divided into five groups that are expected to have a different impact on the resistivity data. Infrastructure groups include the following:

1. Subsurface infrastructure: includes any infrastructure below the ground surface such as buried pipes, electrical lines, conduits, monitoring wells, or continuous subsurface infrastructure

2. Above ground infrastructure: includes any infrastructure on top of the ground surface such as vapor extraction pipelines, buildings, concrete pads (that contain grounded rebar or remesh), extraction well platforms, etc.

3. Overhead infrastructure: includes any overhead utilities supported by poles or structures such as over head power lines, overhead steam pipelines, etc. 
4. Roads: includes both paved and unpaved (dirt or gravel) roads

5. Waste disposal areas: includes all areas that received liquid, solid or mixed waste whether intentional or unintentional.

\subsubsection{Electromagnetic Processing and Plotting}

EM data processing was similar to magnetic processing. Processing occurred in discrete steps, within a Microsoft Excel processing template, so that all data from a previous step could be recovered or viewed. The process included the following steps:

1. Coordinate conversion from a Universal Transverse Mercator to WA State Plane (meters) using U.S. Army Corps of Engineers Corpscon V.6 Software

2. Separating calibration data from field data in individual files using Microsoft Excel

3. Calculation of daily drift by determining the mean value for a static and moving calibration data set using Microsoft Excel

4. Removing data spikes from the individual data files, using Microsoft Excel

5. Normalization of data for each individual data collection file to correct for instrument drift that occurs each time the data acquisition system is restarted

6. Calculation of electrical conductivity using Geophex, Ltd. Invertor software

7. Visualization of results using Surfer V.8 software.

4.3.3.1 Coordinate Conversion. The first step in processing was to convert the GPS coordinate data from a Universal Transverse Mercator to State Plane coordinate system using U.S. Army Corps of Engineers Corpscon V.6 Software. Since EM data were recorded at a higher sampling rate than the GPS data, the resulting GPS coordinate point for each EM data reading was linearly interpolated within the EM data acquisition system.

4.3.3.2 Separating Data Types. After coordinate conversion, the data contained within each file is separated into calibration point data (em.[file date]-[file number]-cal-point.xls), calibration line data (em.[file date]-[file number]-cal-line.xls), and field data (em.[file date]-[file number]wasp-data.xls).

4.3.3.3 Daily Drift Calculation. Data recorded in a static position (cal-point data) is loaded into a Microsoft Excel template that calculates the average reading for the various data field for the duration of the static point data collection. Data spikes are rejected prior to the calculation of data statistics. The same process is performed for data recorded along the calibration line. A summary calibration statistics table, using Microsoft Excel, is used to determine the daily drift for each data file by subtracting the average reading for each data field (cal-point and cal-line) to the first data file collected on this survey. The resulting value is known as the normalization factor.

4.3.3.4 Spike Removal. The field data are placed in a Microsoft Excel template that shows a graphical representation of the data by record number. The sheet also provides data statistics including average, minimum, maximum, and standard deviation. Erroneous large magnitude data spikes are removed in a similar process that was performed with the magnetic data. The 
$9.99 \mathrm{kHz}$ frequency was used as a reference frequency for the spike removal of all three acquired frequencies $(5.01,9.99$, and $20.01 \mathrm{kHz})$. The majority of the EM quadrature data ranged between $-3,000$ and 3,000 and data spikes beyond this range were removed unless they were indicative of high density, high proximity infrastructure. The bulk of the in-phase data population ranged between $-7,000$ and 7,000 and data spikes were typically coincident with data spikes that were rejected for the quadrature data.

4.3.3.5 Data Normalization. The normalization factor for each data field, determined from the daily drift calculation (Refer to Section 4.3.3.3) is input into a Microsoft Excel template that normalizes the data field to the first survey file collected in the project. The day-to-day drift was calculated using the daily line calibration data acquired at the established line calibration site. Slight differences in the daily data records occurred due to environmental or instrument setup changes. Calibration data were acquired while stationary, after an instrument warm up period of no less than 15 minutes. Another calibration data set was collected while following a predetermined survey line. The calibration data record was compared to the mean data value for each data file, and from that an offset value from the previous data file was calculated. It is assumed that the majority of instrument drift occurs as a result of the on/off process and that the instrument reaches a steady state for the duration of the survey. Therefore the normalization process is a simple arithmetic subtraction.

4.3.3.6 Conductivity Calculation. The normalized data output described in Section 4.3.3.5 is input into the Geophex, Ltd. Invertor software in order to calculate the electrical conductivity. The software outputs a comma separated value file that contains the normalized electrical conductivity data.

4.3.3.7 Assembly of a Master Data File. The processed individual data files for each days surveying are appended together into one complete ASCII text file for use in plotting.

4.3.3.8 Data Plotting. Data plotting was performed in the same process listed above for magnetics data. 


\subsection{QUALITY ASSURANCE}

Data quality is controlled through implementation of the CEES-0333, Quality Assurance Plan for Surface Geophysical Exploration Projects along with CEES-0338, Software Management Plan for Surface Geophysical Exploration Projects. The quality assurance plan describes how Columbia Energy and HGI will perform surface geophysical exploration using a graded approach that conforms to applicable requirements from Columbia Energy quality assurance procedures. The Columbia Energy procedures implement the standards set forth in ASME NQA-1, Quality Assurance Requirements for Nuclear Facility Applications and DOE O 414.1C, Quality Assurance.

\subsection{CALIBRATION AND MAINTENANCE OF EQUIPMENT AND INSTRUMENTS}

Calibration and maintenance of equipment used for data collection is addressed in CEES-0360, Surface Geophysical Exploration System Design Description. All quality affecting data are acquired using calibrated and maintained equipment as outlined in the manufacturer recommendations at the time of deployment. The calibration certificate is maintained in the project files.

\subsubsection{Field Logs}

Onsite field notes, maintained by the equipment operators, document the specific instruments used. Electronic logs provide traceable documentation for each data set collected. Information recorded in the electronic field logs include date, instrument identification, operator, and applicable settings for each data set collected. All instruments have current calibration certificates and documentation is maintained in the project files. Instrument calibration frequency and calibration tests performed in the field are documented in CEES-0360. A copy of field logs can be viewed in Appendix B. 
RPP-RPT-42512, Rev. 0

\subsection{ANALYSIS, RESULTS AND INTERPRETATION}

This section contains figures created from the magnetic and EM surveying effort. These figures and the results within are discussed in the subsequent sections.

\subsection{MAGNETIC METHODS}

Within the total magnetic field and gradiometry results, the areas that have no buried metal, which are referred to as background conditions, are represented by yellow hues. Areas too steep to traverse with the G.O. Cart (indicated by orange hatch marks) and "cave in" areas (yellow hatch marks), were not surveyed. Interpreted responses were correlated to available infrastructure maps. The location of the infrastructure was segregated relative to the ground surface (i.e., above or below ground) and interpreted subsurface infrastructure is represented by solid black lines.

\subsubsection{Total Magnetic Field}

Figure 6-1 presents the results of the total magnetic field survey. The results for the survey area west and southwest of SX farm shows no detectable subsurface ferrous materials. Three above ground metallic anomalies are noted, as well as the influence of the associated roadway infrastructure, such as overhead power lines (purple), on the eastern boundary of this area.

The survey area directly south of SX farm, also displays no discernable infrastructure within the total magnetic field results. However, distortion due to above ground utilities (power lines) is noted in the northern portion of this central survey area. Some small dipolar anomalies are observed scattered throughout the southern portion of this area, indicative of metallic debris and surface metal, such as fence and sign posts that are unlikely to affect resistivity data analysis.

The area surveyed east of SX farm presents the greatest amount of discernable infrastructure that are likely to affect resistivity data analysis. Six major linear features are interpreted, four running approximately east to west, one trending north-south along the road, and one trending from northeast to southwest in the upper northeastern corner of the site.

In general the total magnetic field becomes saturated when near the SX farm perimeter and the associated above ground infrastructure (overhead power lines), severely limiting interpretation in these areas. This is indicated by the large swaths of purple contours in the direct vicinity of the farm.

NOTE: The color scale used for the total field is specifically designed to distinguish subsurface features of interest that may influence resistivity results for the specific survey area. It is therefore not consistent with color scales used on previous magnetic surveys conducted on the Hanford Site.

In order to determine the possible impact of the detected utilities, it is necessary to correlate the features to known infrastructure. Figure 6-2 shows the interpretation of magnetic features along with site infrastructure drawings. All interpreted features correspond with infrastructure maps 
with the exception of interpreted feature \#2, which is indicative of a pipeline feature. Results show that the areas west and south of the SX farm are free of subsurface infrastructure.

\section{Figure 6-1. Total Magnetic Field Results with Interpreted Infrastructure.}

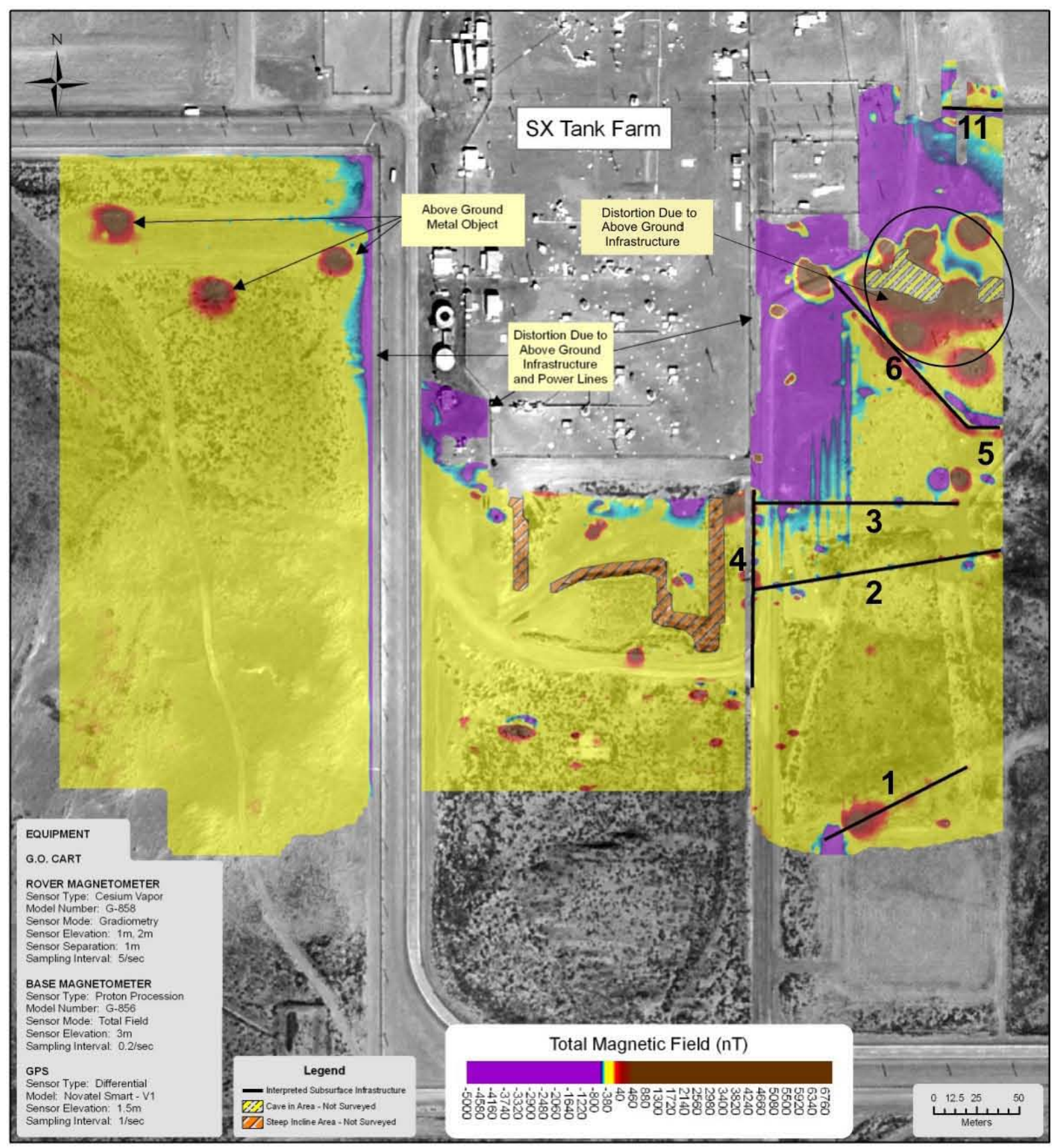


RPP-RPT-42512, Rev. 0

Figure 6-2. Total Magnetic Field Interpreted and Known Infrastructure.

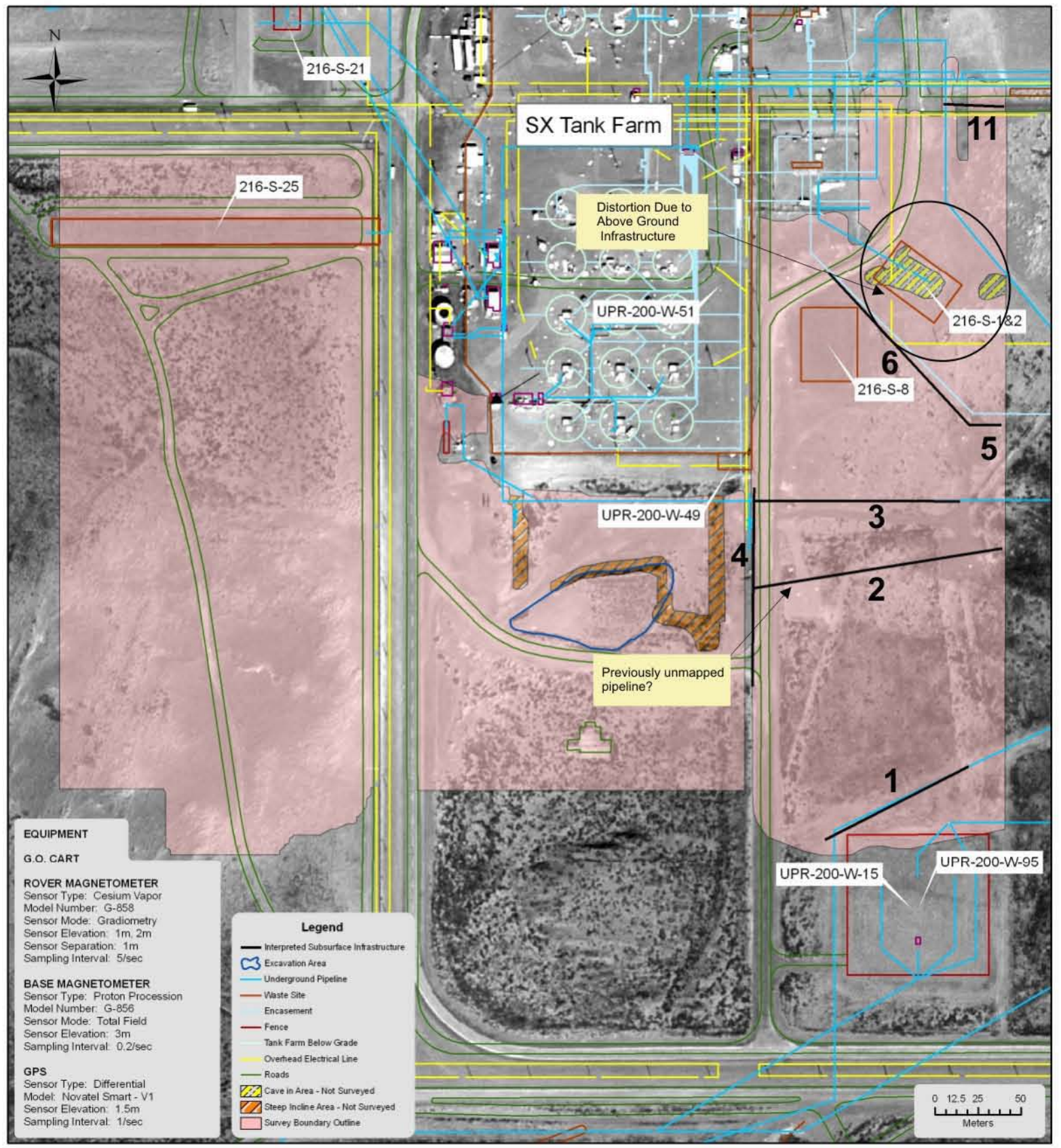




\subsubsection{Vertical Magnetic Gradient}

The vertical magnetic gradient is calculated by differencing the magnetic field of the bottom sensor and the top sensor, divided by the separation distance of 3.3 feet ( 1 meter). This process is better suited for detecting and mapping features that are closer to the surface (e.g., pipes), and the measurements are typically not as likely to be saturated as the total field measurement from the top sensor alone. Several linear anomalies appear in the data that indicate the presence of subsurface infrastructure that will likely influence resistivity surveying results.

The same series of plots that correlate MAG features to infrastructure drawings are shown for the vertical magnetic gradient. Figure 6-3 presents the geophysical results of the gradiometry survey. The survey area west and southwest of SX farm shows no detectable subsurface ferrous materials. Three above ground metallic anomalies are observed, as well as some small influence associated with the roadway, such as overhead power lines (purple), on the eastern boundary of this area. The fencing around the $216-\mathrm{S}-25$ area is also visible.

The survey area directly south of SX farm, also continues to display no discernable infrastructure within the vertical gradient results. Additionally, the distortion due to above ground utilities is considerably less than that of the total magnetic field data. The small dipolar anomalies south of the SX farm are indicative of metallic debris and surface metal, such as fence and sign posts.

The area surveyed east of SX farm presents the greatest amount of discernable infrastructure. The same six major linear features identified with the total field magnetics, are detectable; however, they are more refined and can be traced further into the areas that were saturated within the total field magnetics results near the SX farm fence line.

NOTE: The color scale used for the vertical gradient is specifically designed to distinguish subsurface features of interest that may influence resistivity results for the specific survey area. It is therefore not consistent with color scales used on previous magnetic surveys conducted on the Hanford Site.

Figure 6-4 shows the interpreted results for the vertical magnetic gradient survey along with layers from available infrastructure drawings. The results from the vertical magnetic gradient correlate well with the infrastructure maps as well as provide possible infrastructure locations not previously documented. 
Figure 6-3. Vertical Magnetic Gradient Shown with Interpreted Infrastructure.

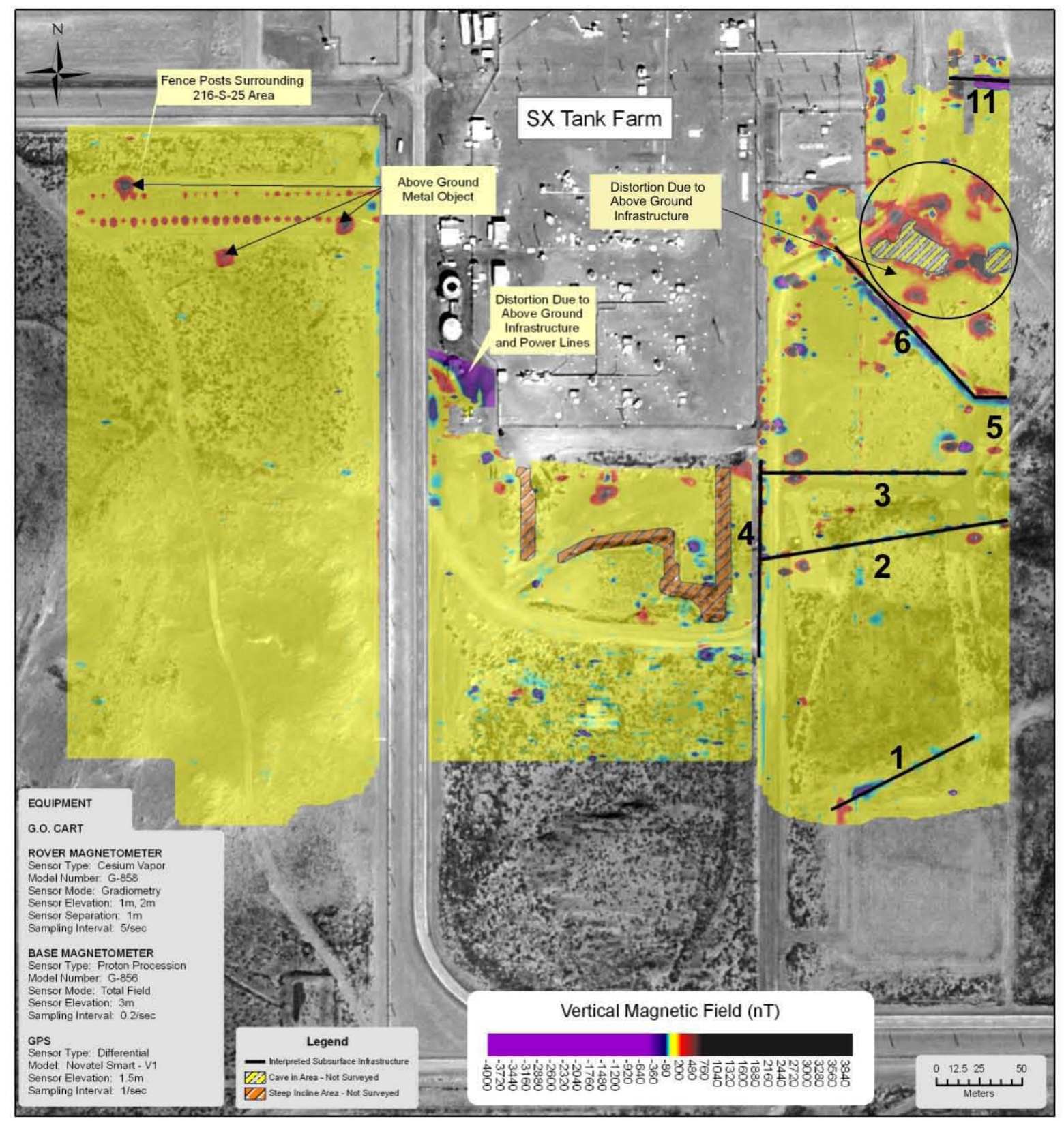


Figure 6-4. Vertical Magnetic Gradient Interpreted and Known Infrastructure.

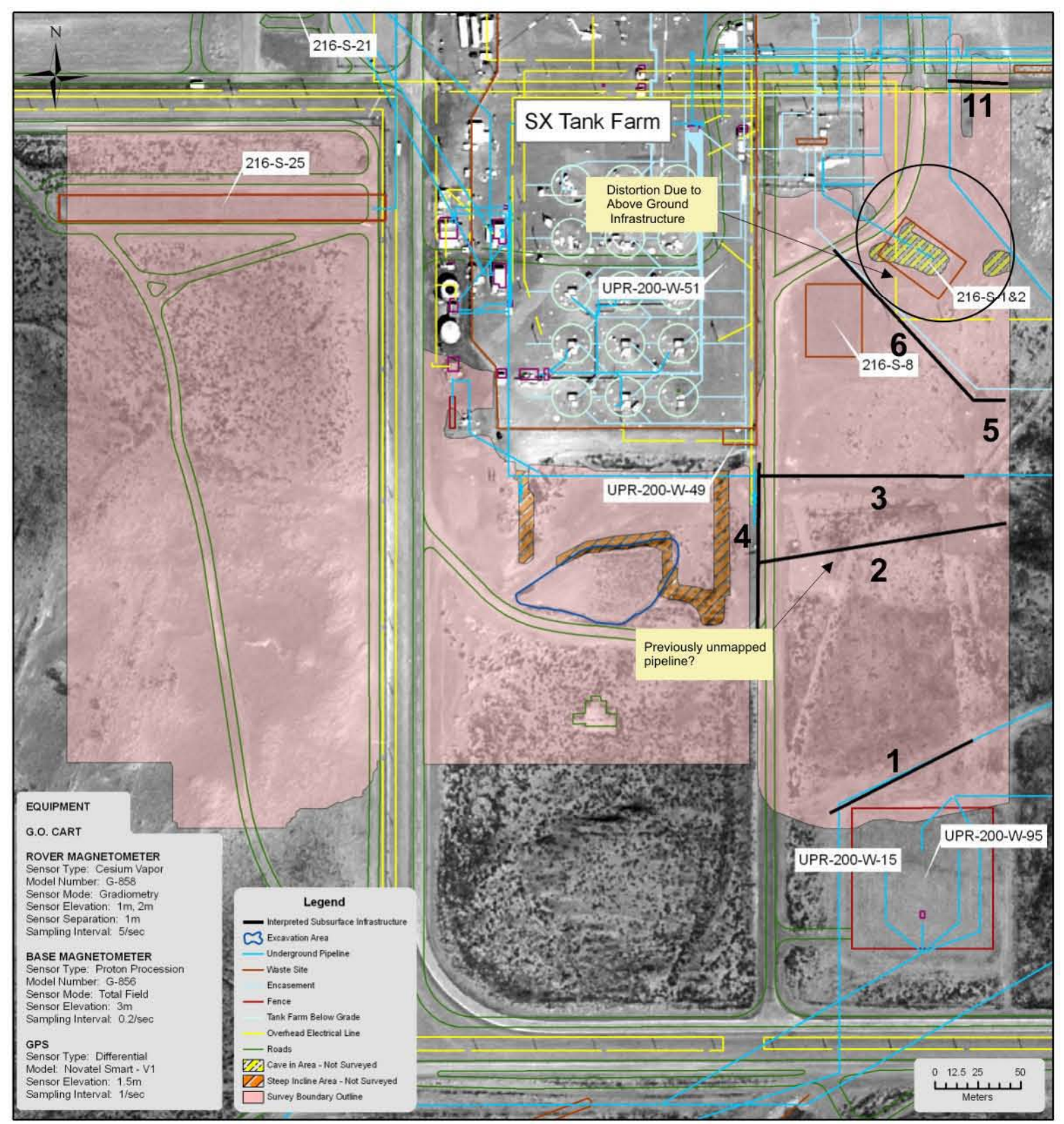


RPP-RPT-42512, Rev. 0

\subsection{ELECTROMAGNETIC INDUCTION}

\subsubsection{Electrical In-Phase}

Electrical in-phase measurements from EM induction were acquired for the frequencies of 5.01, 9.99 , and $20.01 \mathrm{kHz}$. The results for the three frequencies are similar enough that for this report the $9.99 \mathrm{kHz}$ frequency was selected for presentation. The data were contoured to show the spatial representation of relevant subsurface features.

In general, the figures show linear anomalies that are indicative of subsurface infrastructure. Most of the linear features correlate well with available Hanford infrastructure maps. This provides confidence that most of the linear features detected by the EM in-phase survey, but are not shown on the available maps, are likely to be subsurface utilities. The EM in-phase figures use a color scheme that represents variations in the data. Hues ranging from yellow to red represent high electrical in-phase responses. Green, light blue, and dark blue hues represent low electrical in-phase responses and yellow represents background. The series of color contour result maps are designed to allow direct interpretation. EM data were collected in several grids that were normalized to each other to reduce drift between each data collection period. Therefore the results presented in this report reflect a normalized value following a data processing regiment discussed in Section 4.3.

Figure 6-5 presents the results of the In-Phase EM survey. The results for the survey area west and southwest of SX farm show no detectable subsurface materials. Influence of the associated roadway infrastructure is noted, on the eastern boundary of this area. Additionally, contributions from the $216-\mathrm{S}-25$ area fencing can be seen.

The survey area directly south of SX farm, also displays no discernable linear features indicative of infrastructure within the $9.9 \mathrm{kHz}$ in-phase results. However, distortion due to above ground utilities and infrastructure is noted in the northern portion of this central survey area. Some small dipolar anomalies are observed scattered throughout the this area, indicative of metallic debris and surface metal, such as fence and sign posts.

The area surveyed east of SX farm presents the greatest amount of discernable infrastructure, with the best resolution of subsurface targets when compared to the other methods used. Nine separate and distinct subsurface linear features are noted, with the northern area providing the greatest detail.

NOTE: The color scale used for the electrical in-phase survey is specifically designed to distinguish subsurface features of interest that may influence resistivity results for the specific survey area. It is therefore not consistent with color scales used on previous magnetic surveys conducted on the Hanford Site.

Figure 6-6 shows the interpreted features for EM in-phase with infrastructure layers from available infrastructure drawings. As with the results of the magnetic survey, the EM mapping shows no response between interpreted feature \#9 and interpreted feature \#12 where a pipeline is indicated on the provided infrastructure maps. It appears that the section of pipeline was removed or the map was incorrect. Interpreted feature \#2 is indicative of a pipeline response and is verified by the magnetic survey results, but is not indicated on the provided infrastructure maps. 
Figure 6-5. Electrical In-Phase (10 kHz) Results with Interpreted Features.

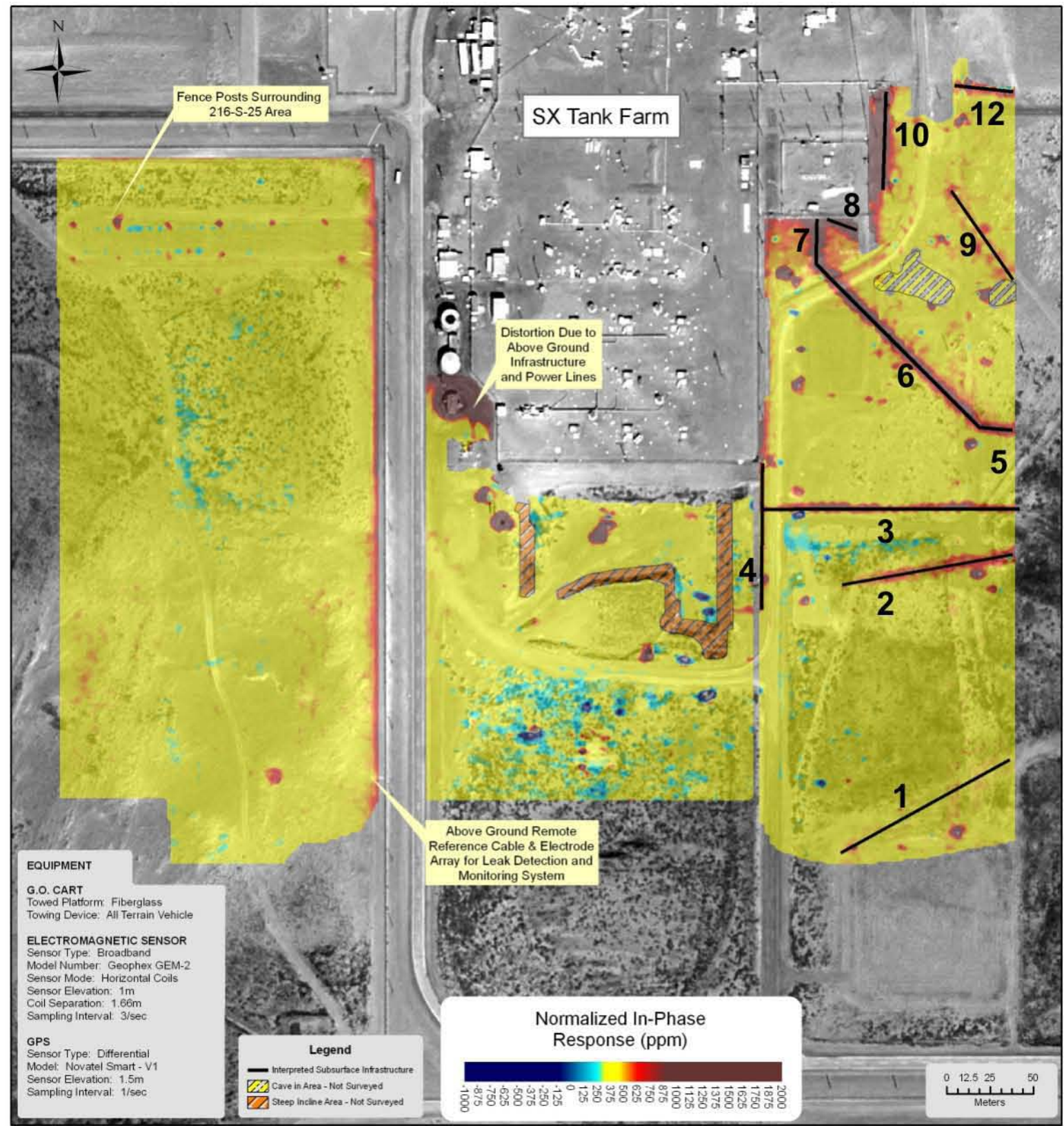


Figure 6-6. Electrical In-Phase (10 kHz) Interpreted and Known Features.

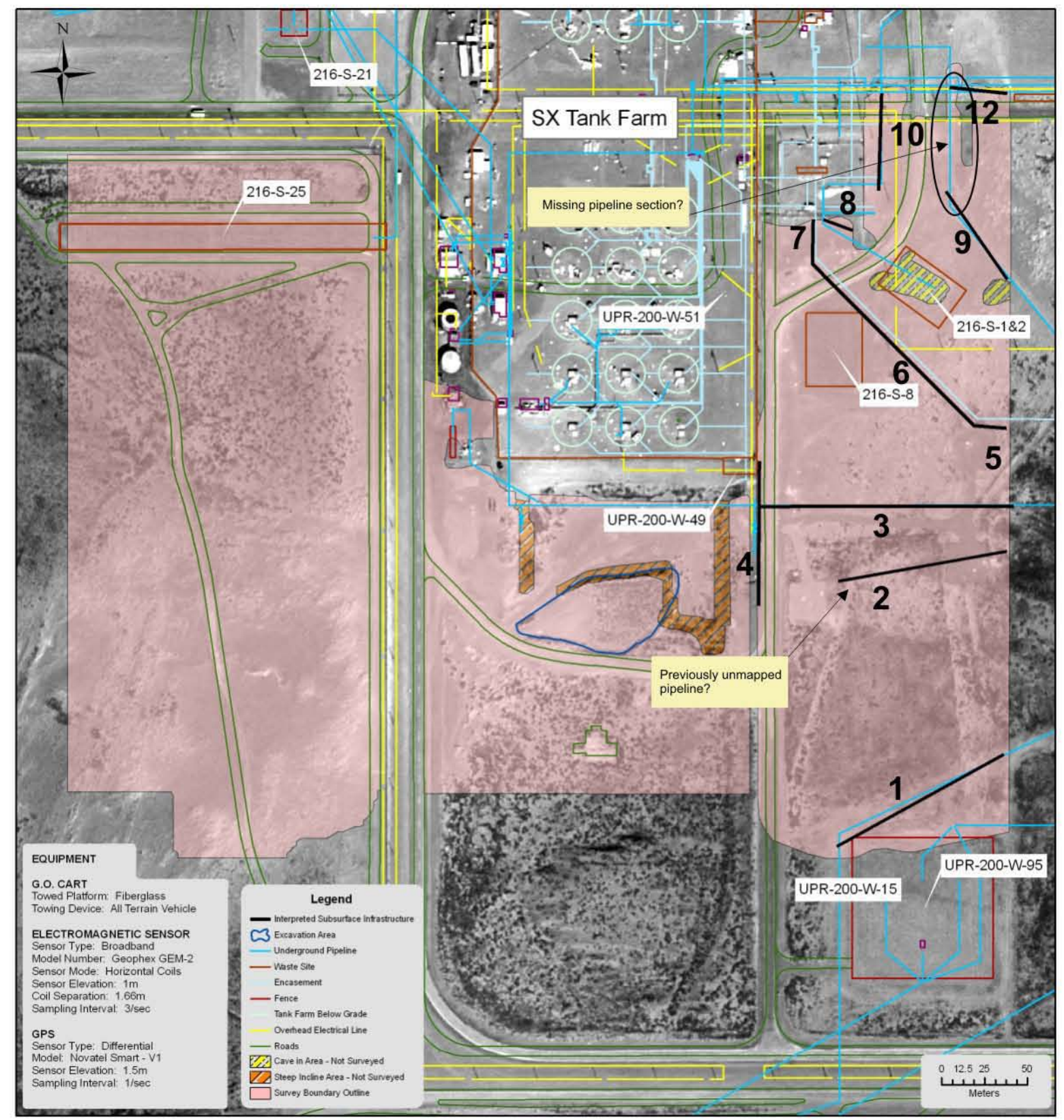




\subsubsection{Electrical Conductivity}

Electrical conductivity measurements were acquired for the frequencies of 5.01,9.99, and $20.0 \mathrm{kHz}$. The $9.99 \mathrm{kHz}$ frequency is representative of all three frequencies and is selected for presentation in this report. Unlike the MAG and EM in-phase data, anomalous responses in the electrical conductivity could result from increased soil moisture or salt deposits, in addition to the presence of ferrous and non-ferrous metals. The data were contoured to show the spatial representation of relevant subsurface features.

In general, the figures show linear anomalies that correlate well with the EM in-phase and magnetic results. However, the EM conductivity results also show a response from the above ground remote reference cable and electrode array for the leak detection and monitoring system, as seen in the area to the southwest of SX tank farm. Scattered responses from the fence posts surrounding the 216-S-25 area, west of SX tank farm, are also present. In addition, there are a few responses to overhead power lines; an example of which can be seen on Figure 6-7 south of interpreted feature \#10 and north of interpreted feature \#6. Most of the linear features correlate well with available Hanford infrastructure maps. This provides confidence that most of the linear features detected by the EM survey, but are not shown on the available maps, are likely to be subsurface utilities.

The figures use a color scheme that best represents variations within the data. Hues ranging from red to brown and blue to purple represent high electrical conductivity values and yellow represents background values. The series of color contour result maps are designed to allow direct interpretation. EM data were collected in several grids that were normalized to each other to reduce drift between each data collection period. Therefore, the results presented in this report reflect a normalized value following a data processing regimen discussed in Section 4.3 of this report.

NOTE: The color scale used for the electrical conductivity survey is specifically designed to distinguish subsurface features of interest that may influence resistivity results for the specific survey area. It is therefore not consistent with color scales used on previous magnetic surveys conducted on the Hanford Site.

A plot that presents interpreted EM conductivity features is shown in Figure 6-7. Figure 6-8 shows the results for EM conductivity with infrastructure layers from available infrastructure drawings. 
Figure 6-7. Electrical Conductivity $(10 \mathrm{kHz})$ Shown with Interpreted Infrastructure.

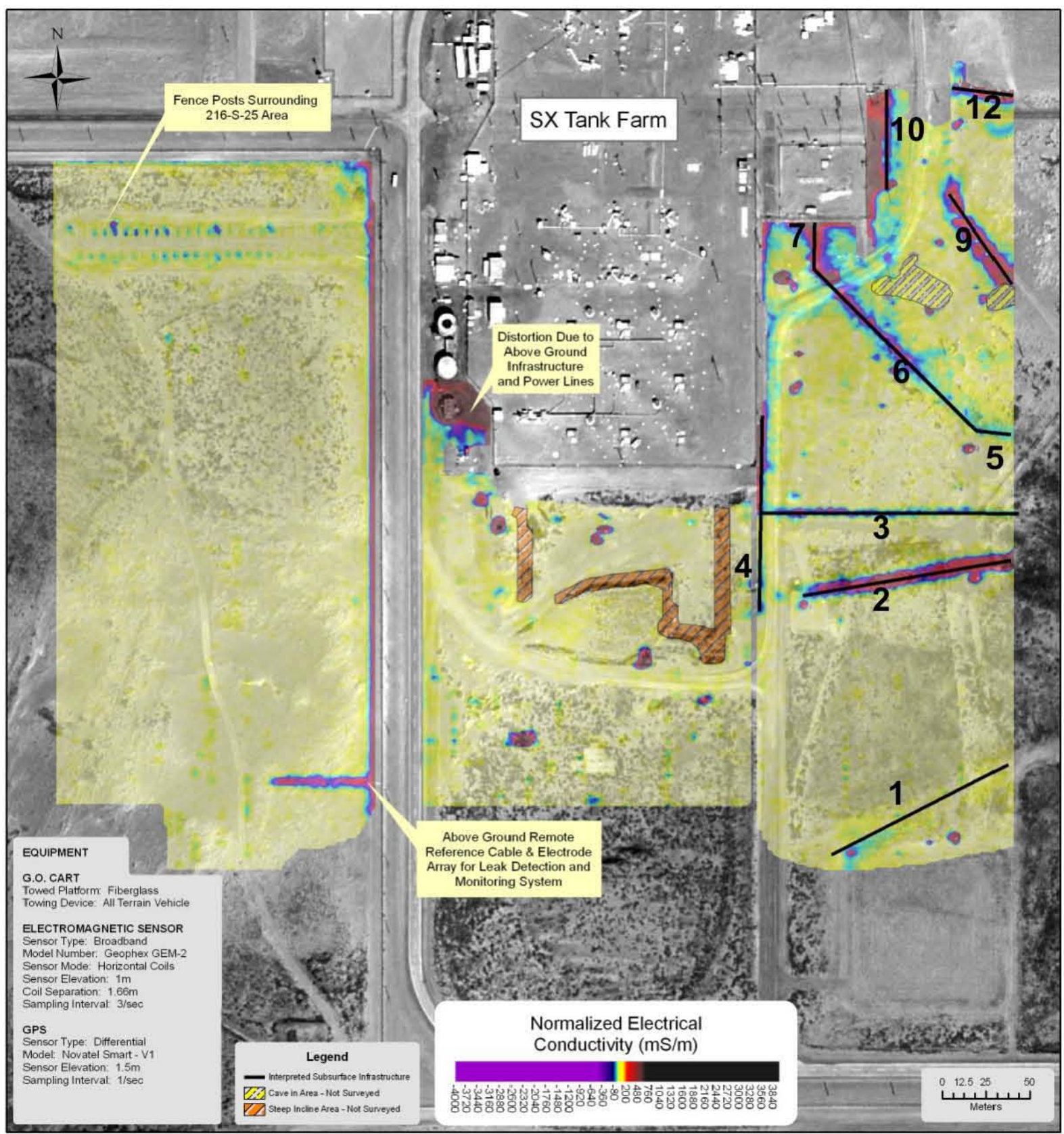


Figure 6-8. Electrical Conductivity $(10 \mathrm{kHz})$ Interpreted Results Shown with Infrastructure from Drawings.

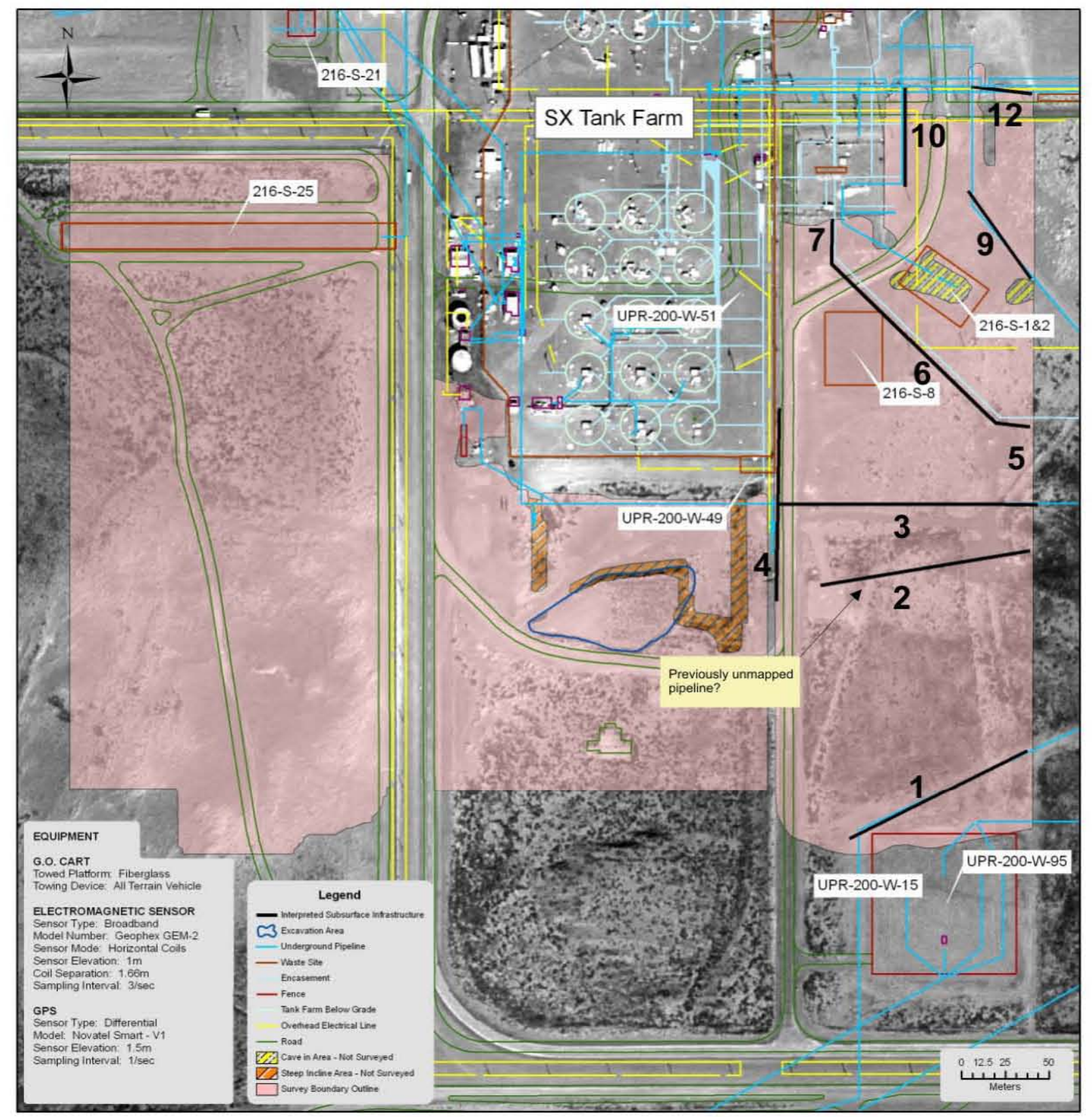

\subsection{SUMMARY OF MAG AND EM FEATURES}

A summary of features identified from the EM and MAG Interpretation, after correlation to available Hanford utility maps, is presented in Figure 6-9. The individual interpreted features from the different geophysical methods have been superimposed onto one plan view image. The 
results display positive agreement between the methods for the majority of features. Features that do not correlate between the EM and MAG surveys provide additional segregation of material properties that will be used to support resistivity data interpretation.

Figure 6-9. Summary of Interpreted Features from G.O.Cart ${ }^{\mathrm{TM}}$ Survey.

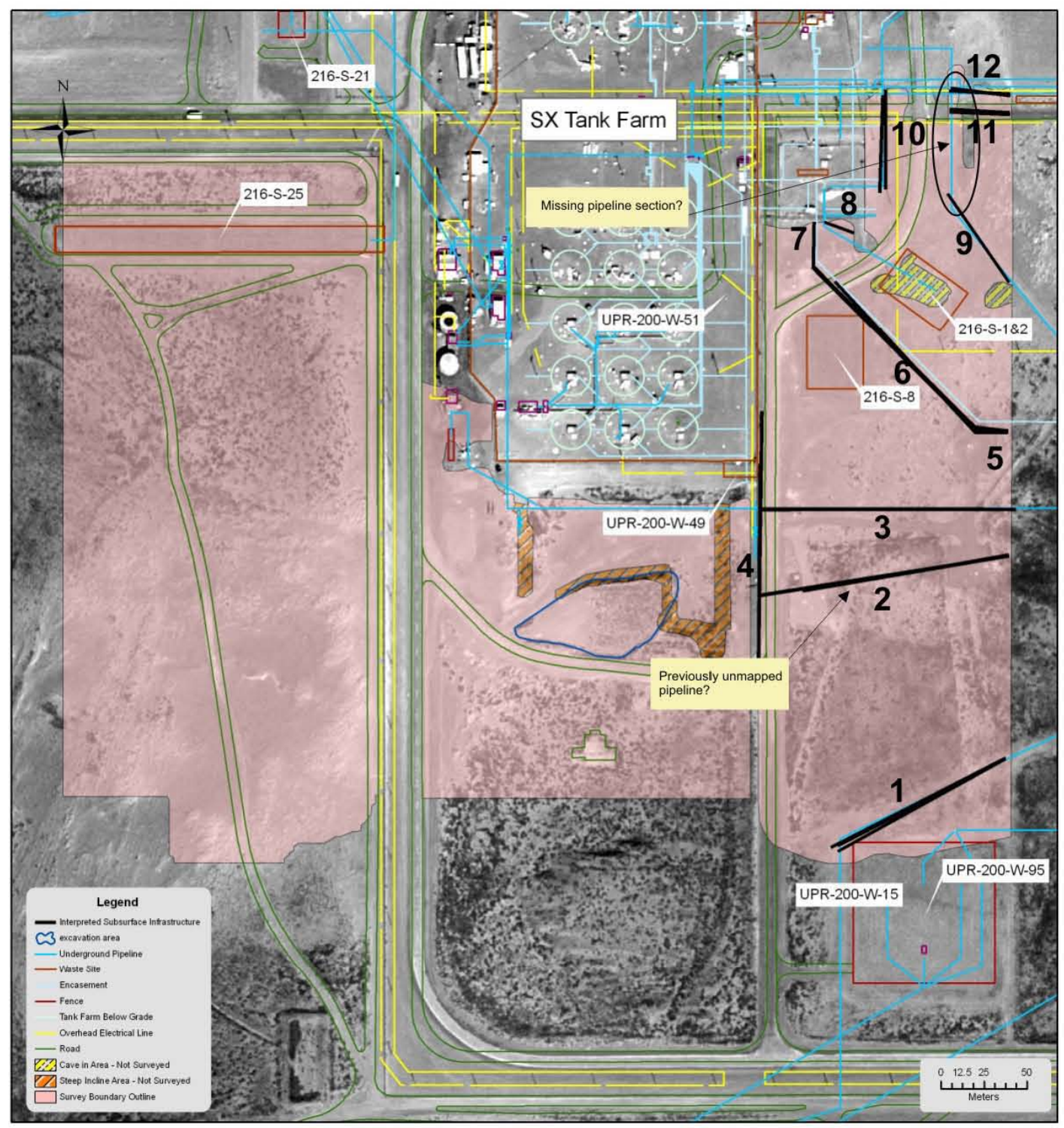




\subsection{CONCLUSIONS}

Results of the surveying revealed several subsurface features that are interpreted as buried pipes. The contoured data from EMs provided the best data for delineating continuous linear features that are indicative of subsurface infrastructure such as pipes or utilities. The contoured magnetic data provided additional agreement for many of the linear features while also providing information about soil properties, surface structures that have metallic grounding and sporadic surface metal debris.

Survey results show a high concentration of infrastructure that will likely influence resistivity results primarily in the areas to the east and southeast of SX tank farm. The areas west and south of the SX tank farm are nearly free of subsurface infrastructure and will be most suitable for resistivity surveying.

Results of the G.O. Cart survey and associated interpreted linear feature or pipe locations are used in the interpretation of resistivity inversion modeling results. Comparison of inversion results with plots of interpreted features based on the EM and MAG data allows for consideration of the potential effects of these artifacts on the interpretations of inverted resistivity results. If, for example, a low resistivity target is seen directly beneath a grouping of several pipes, then the resistivity results should be viewed carefully with anticipated uncertainty in an interpreted electrolytic conduction phenomenon. 
RPP-RPT-42512, Rev. 0

\subsection{REFERENCES}

ASME NQA-1, 1994, Quality Assurance Program Requirements for Nuclear Facilities, American Society of Mechanical Engineers, New York, New York.

Breiner, S., 1973, Applications Manual for Portable Magnetometer, Geometrics, Inc, San Jose, California. (www.geometrics.com/Literature/Magnetics/magnetics.html)

CEES-0333, 2006, Quality Assurance Plan for Surface Geophysical Exploration Projects, Rev. 0, Columbia Energy \& Environmental Services Inc., Richland, Washington.

CEES-0338, 2006, Software Management Plan for Surface Geophysical Exploration Projects, Rev. 0, Columbia Energy \& Environmental Services, Inc., Richland, Washington.

CEES-0360, 2007, Surface Geophysical Exploration System Design Description, Rev. 0, Columbia Energy \& Environmental Services, Inc., Richland, Washington.

DOE O 414.1A, 2001, Quality Assurance, U.S. Department of Energy, Washington, D.C.

Grant F.S. and G.F. West, 1965. Interpretation Theory in Applied Geophysics, McGraw-Hill Book Co. New York.

HNF-5507, 2000, Subsurface Conditions for B-BX-BY Waste Management Area, Rev. 0, Fluor Hanford, Inc., Richland, Washington.

RPP-PLAN-36704, Work Plan for Surface Geophysical Exploration of the SX Tank Farm and Surrounding Areas, Rev. O, Washington River Protection Solutions LLC, Richland, Washington.

RPP-RPT-38321, Surface Geophysical Exploration of S and SX Tank Farms at the Hanford Site: Results of Background Characterization with Ground Penetrating Radar.

Schlinger, C.M., 1990, "Magnetometer and Gradiometer Surveys for Detection of Underground Storage Tanks." Bulletin of the Association of Engineering Geologist, Vol. XXVII:37-50.

Telford, W.M., L.P. Geldart, and R.E. Sherriff, 1990, Applied Geophysics, Cambridge University Press, Cambridge, United Kingdom.

Won, I.J., 1980. "A wideband electromagnetic exploration method - Some theoretical and experimental results." Geophysics 45 (3):928-940. 
RPP-RPT-42512, Rev. 0

APPENDIX A

SUPPLEMENTAL PLOTS 
Figure A-1. Electrical Conductivity (5KHz) Shown with Interpreted Infrastructure.

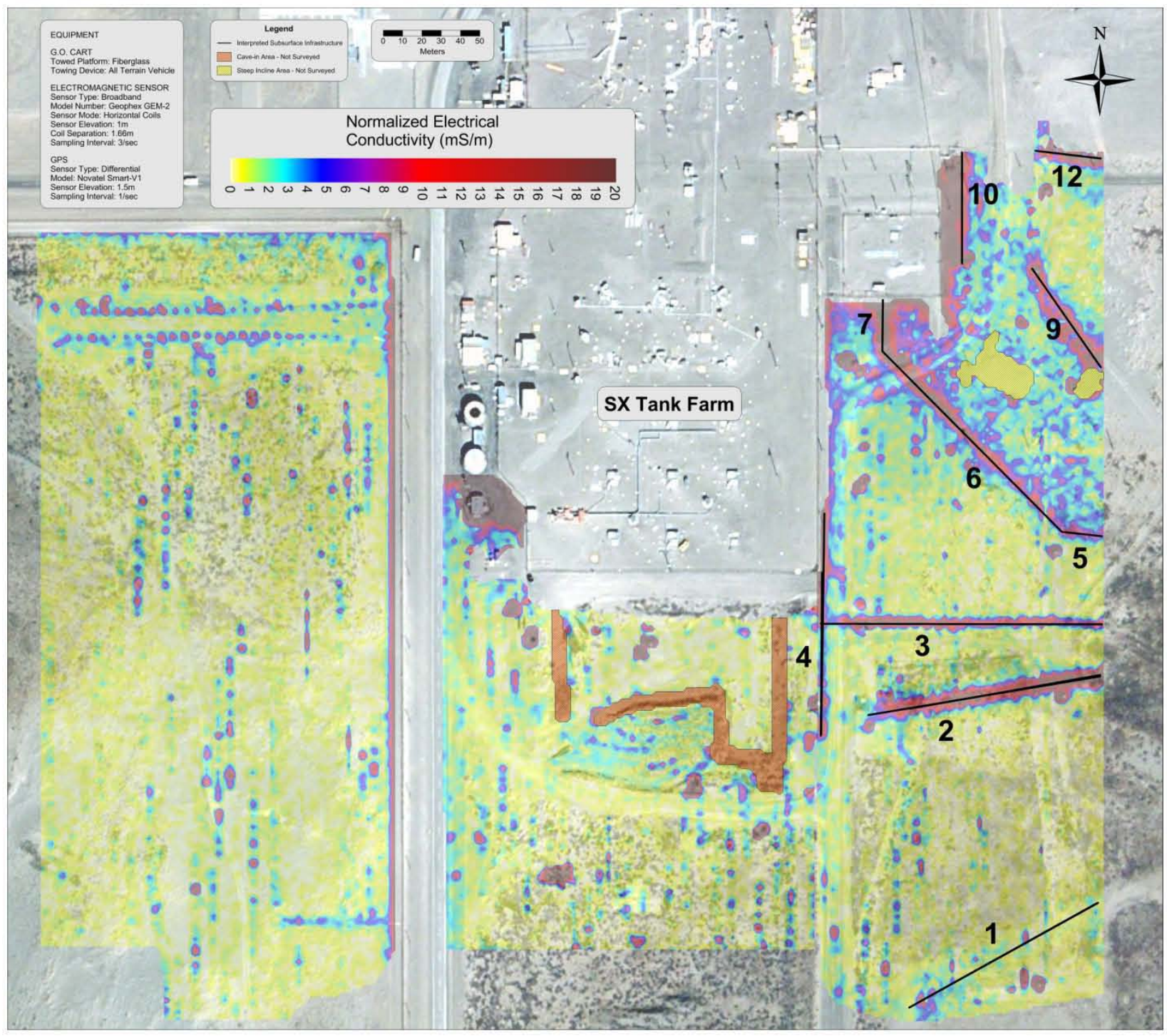


RPP-RPT-42512, Rev. 0

Figure A-2. Electrical Conductivity (20KHz) Shown with Interpreted Infrastructure.

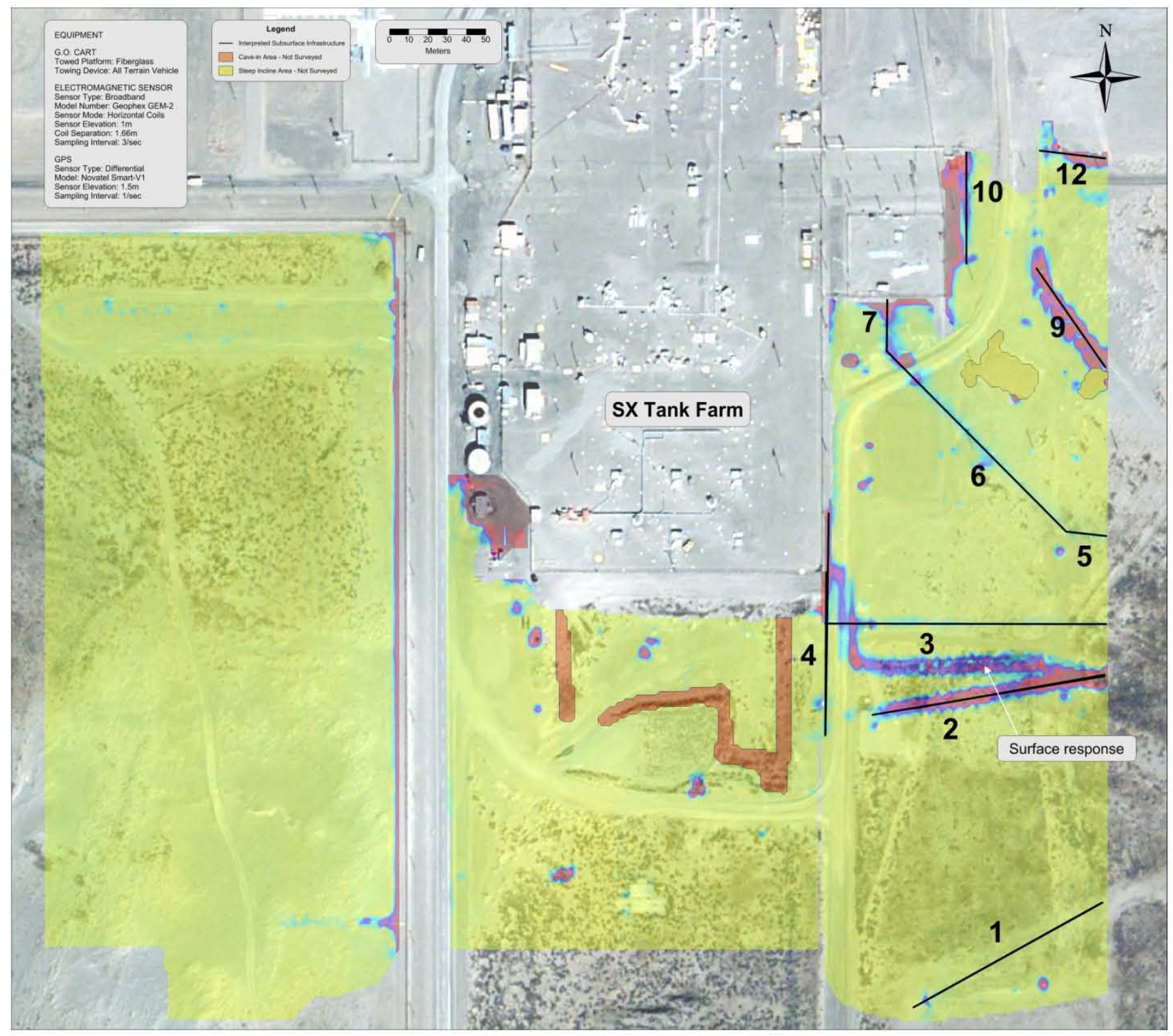


RPP-RPT-42512, Rev. 0

Figure A-3. Electrical In-Phase (5KHz) Results with Interpreted Features.

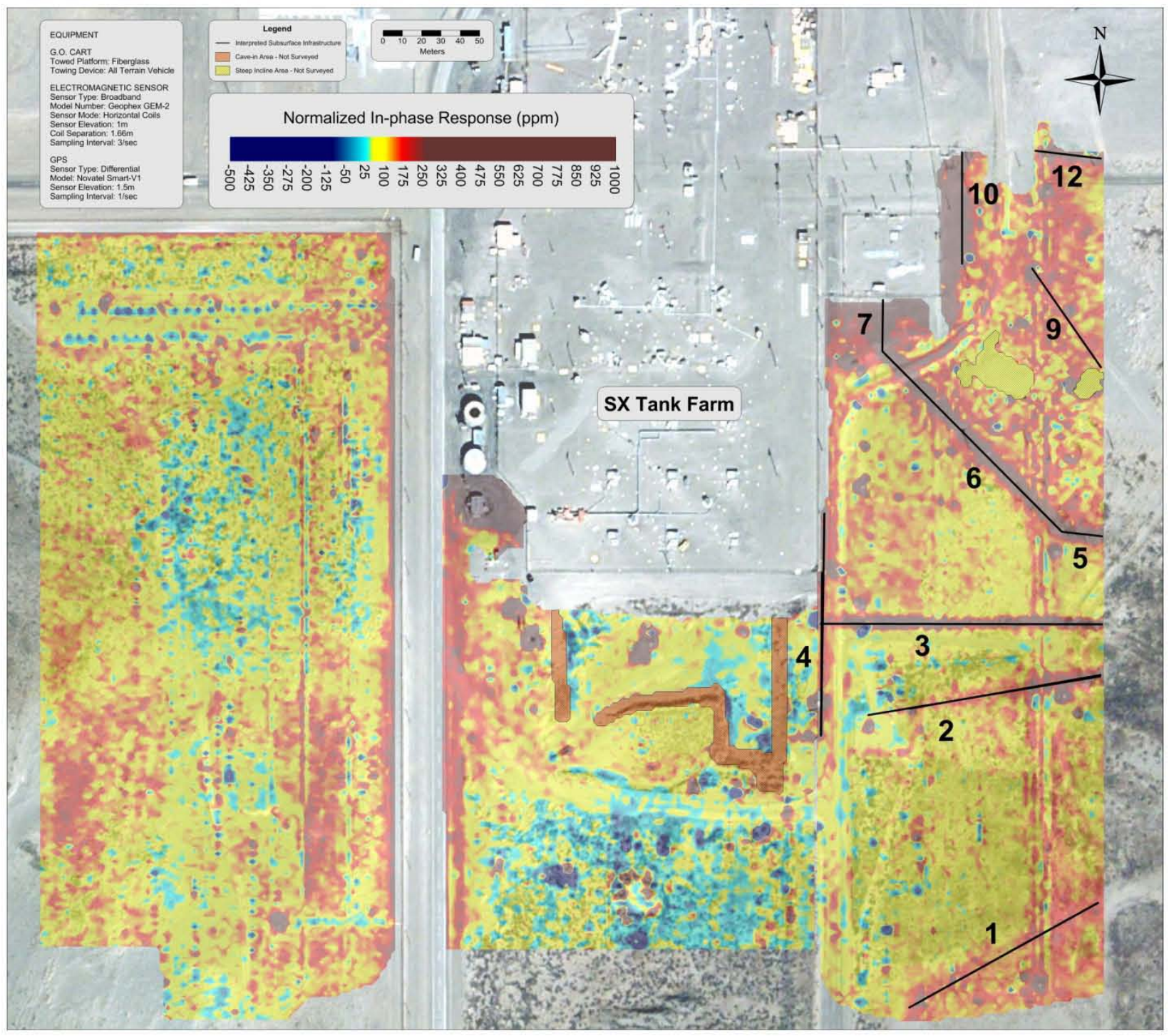


RPP-RPT-42512, Rev. 0

Figure A-4. Electrical In-Phase (20KHz) Results with Interpreted Features.

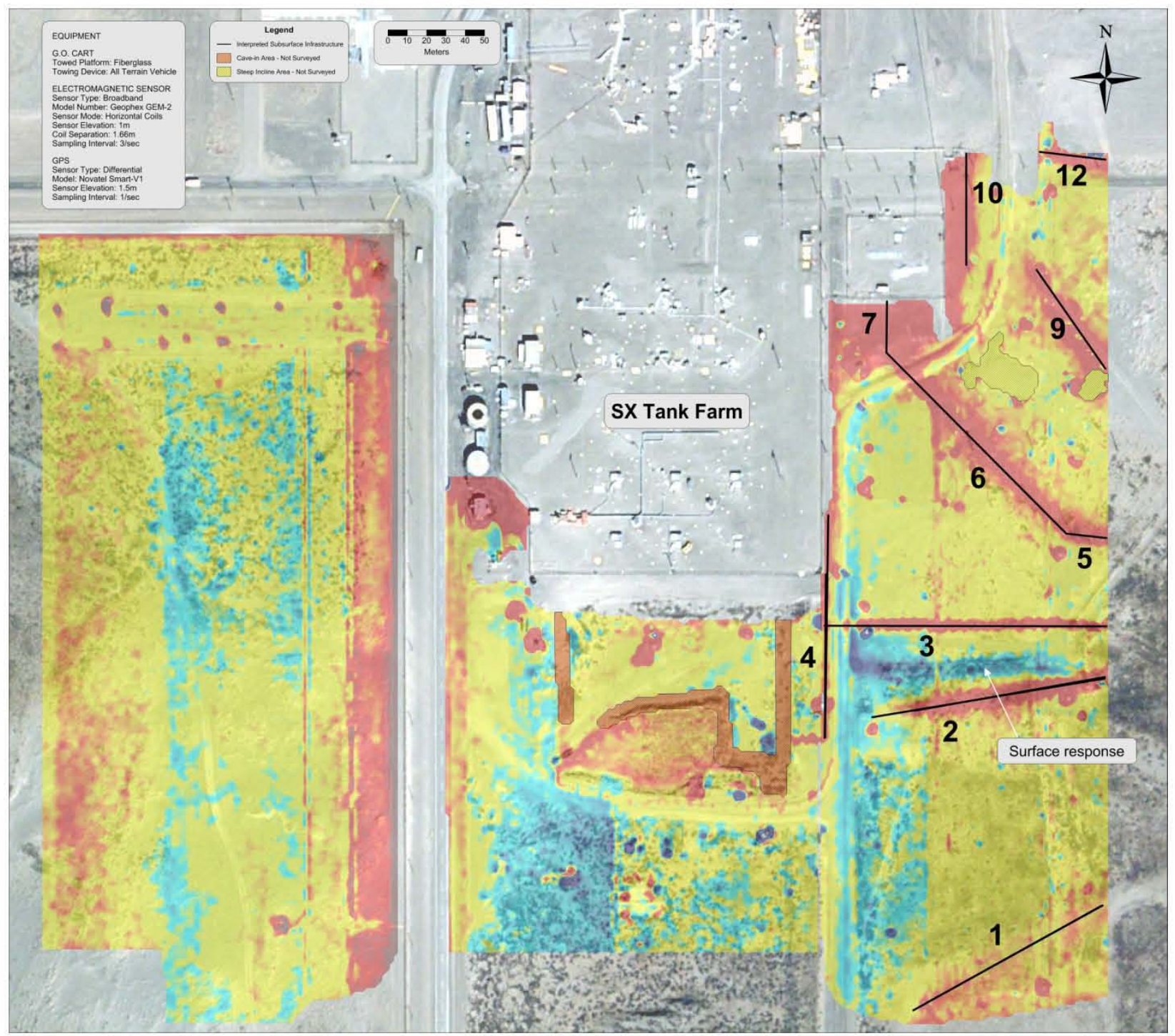


RPP-RPT-42512, Rev. 0

APPENDIX B

FIELD FORMS 


\begin{tabular}{|c|c|c|}
\hline \multicolumn{3}{|l|}{ GENERAL } \\
\hline $\begin{array}{l}\text { Job Number: } \\
\text { 2009-001 }\end{array}$ & $\begin{array}{l}\text { Project Site: } \\
\text { SX Farm }\end{array}$ & $\begin{array}{l}\text { Field Operator(s): } \\
\text { rbrauchla }\end{array}$ \\
\hline $\begin{array}{l}\text { Date: } \\
03 / 11 / 2009\end{array}$ & $\begin{array}{l}\text { Start Time: } \\
10: 30\end{array}$ & $\begin{array}{l}\text { End Time: } \\
15: 00\end{array}$ \\
\hline \multicolumn{3}{|l|}{ DATA FILES } \\
\hline \multicolumn{3}{|c|}{$\begin{array}{l}\text { File Name: } 856.03 \cdot 11.2009 \text { b.stn } \\
\text { MAG ROVER: }\end{array}$} \\
\hline \multicolumn{3}{|c|}{$\begin{array}{l}\text { Download File Name (w/extension): IISnowwhiteljobs\2009-001_004 SX Farm STS } \\
\text { Resistivity\DatalG.O.Cart\3.11.2009\Mag\Step 1 - Raw UTM Datal858.03.11.2009a.bin }\end{array}$} \\
\hline \multicolumn{3}{|c|}{$\begin{array}{l}\text { Diurnally Corrected Exported File Name (w/extension): IISnowwhiteljobs\2009-001_004 SX Farm } \\
\text { STS Resistivity\DatalG.O.Cart13.11.2009\Mag\Step 1 - Raw UTM Datal858.03.11.2009awithbase.dat }\end{array}$} \\
\hline \multicolumn{3}{|c|}{$\begin{array}{l}\text { GPS Converted (to WA State Plane) File Name (w/extension): IISnowwhiteljobs\2009-001_004 } \\
\text { SX Farm STS Resistivity\DatalG.O.Cart13.11.2009\Mag\Step 2 - Raw WASP } \\
\text { Datal858.03.11.2009awithbase.WASP.dat }\end{array}$} \\
\hline \multicolumn{3}{|l|}{ EM: } \\
\hline \multicolumn{3}{|c|}{$\begin{array}{l}\text { Download File Name (w/extension): IISnowwhiteljobs\2009-001_004 SX Farm STS } \\
\text { Resistivity\DatalG.O.Cart13.11.2009\EMIStep 1 - Raw UTM Datalem.03.11.2009a.gbf }\end{array}$} \\
\hline \multicolumn{3}{|c|}{$\begin{array}{l}\text { Exported File Name (w/extension): IISnowwhiteljobs\2009-001_004 SX Farm STS } \\
\text { Resistivity\DatalG.O.Cart 3.11.2009\EMIStep 1 - Raw UTM Datalem.03.11.2009a.csv }\end{array}$} \\
\hline \multicolumn{3}{|c|}{$\begin{array}{l}\text { GPS Converted (to WA State Plane) File Name (w/extension): IISnowwhiteljobs\2009-001_004 } \\
\text { SX Farm STS ResistivitylDatalG.O.Cartl3.11.2009\EMIStep 2 - Raw WASP } \\
\text { Datalem.03.11.2009a.WASP.csv }\end{array}$} \\
\hline \multicolumn{3}{|c|}{ SURVEY INSTRUMENTS } \\
\hline \multicolumn{3}{|c|}{ GPS INSTRUMENT } \\
\hline \multicolumn{2}{|l|}{ Model: $\quad$ Smart V-1 } & Output Data Frequency: $20 \mathrm{~Hz}$ \\
\hline \multicolumn{2}{|l|}{ Manufacturer: Novatel } & ction: $\square$ RTK $\square$ DGPS $\square$ WAAS \\
\hline \multicolumn{2}{|c|}{ Serial Number: NBL08370019 } & ider/Source: OmniSTAR \\
\hline
\end{tabular}

C:IDocuments and Settingslbcubbage.STOOGENET\Desktopl03.11.2009 GO Cart FIELD FORM.doc Page 1 of 3 


\section{MAGNETIC (MAG) INSTRUMENT}

Base Magnetometer

Model: G-856

Manufacturer: Geometrics

Serial Number: 278144

Sample Rate: $0.1 \mathrm{~Hz}$ (10 seconds)
Rover Magnetometer

Model: G-858G

Manufacturer: Geometrics

Serial Number: 29502

Sample Rate: $10 \mathrm{~Hz}$

\section{ELECTROMAGNETIC (EM) INSTRUMENT}

Model: GEM-2

Manufacturer: Geophex

Serial Number: GEM2-1400
Frequencies Used: $5010 \mathrm{~Hz} \quad 9990 \mathrm{~Hz}$ $20010 \mathrm{~Hz}$

Sample Rate: $\quad 3 \mathrm{~Hz}$

\section{PRE-OPERATIONAL CHECKLIST}

\section{GPS:}

$\bigotimes$ Connect power to GPS and verify operational status

Verify satellite reception, accuracy and reception of desired correction (WAAS, DGPS, etc)

\section{MAG BASE:}

$\bigotimes$ Attach fresh battery to Base Magnetometer and verify operational status and signal level

Clear memory and verify correct Julian date/time

$\triangle$ Set automatic measurements to a cycle time of 10 seconds

$\bigotimes$ Start automatic measurements and visually verify that 3 successive measurements are collected

\section{MAG ROVER:}

$\triangle$ Attach fresh battery to Gradiometer and power on allowing coils to energize for 5 minutes

$\bigotimes$ Verify battery level, memory space, and operational status

$\triangle$ Perform visual inspection of GPS data string as received by the Gradiometer

$\bigotimes$ Perform magnetometer test on both sensors to ensure a signal is transmitted

$\triangle$ Verify correct date/time and synchronization of MAG Base and Rover Clocks

EM:

$\bigotimes$ Power EM instrument and verify battery charge by viewing battery status indicator

Confirm GPS Communication to EM Instrument (G symbol on console display)

Check operational status of EM Instrument

Clear memory and verify correct frequencies

\section{DAILY CALIBRATION CHECKLIST}

\section{STATIONARY CALIBRATION:}

$\bigotimes$ Set Mag base, rover and EM instruments to record

$\bigotimes$ Drive to calibration site and park G.O Cart at the same stationary location

$\bigotimes$ Clear memory for EM and Rover magnetometer and restart data collection

C:IDocuments and Settingslbcubbage.STOOGENETDesktopl03.11.2009 GO Cart FIELD FORM.doc Page 2 of 3 
$\bigotimes$ With instruments recording, remain stationary for a minimum of 15 minutes

$\bigotimes$ With instruments recording, drive to start of Moving Calibration Line

\section{MOVING CALIBRATION:}

$\bigotimes$ With instruments recording, drive G.O. Cart along Moving Calibration Line at no more than 3 miles per hour (normal walking pace)

$\bigotimes$ With instruments recording, drive G.O. Cart to start of survey area and complete surveying

\section{GENERAL NOTES}

Environmental/Weather Conditions:

Cold and mostly sunny

Survey Area Notes (Infrastructure Location, etc.):

Survey Area: 2 (western part). The terrain varied from flat to steep hills and large dunes. egitation was moderate in most places. Major obstacles included steep slopes, large bushes, posts, outbuildings, wells, and rocks as well as the fences surrounding the URMA in the north part of the survey area.

\section{EQUIPMENT FAILURES}

\section{Description of Equipment Failure:}

Yesterday: Two hardware failures (EM charger, and 858 Mag Data Mapper).

Today: Loss of $14 \%$ of GPS data due to bad connection with GPS battery

\section{Resolution of Equipment Failure:}

Replaced faulty hardware. Battery connection fixed. Will have to recollect data because when GPS turned on after disconnect, DGPS could not be verified.

\section{SIGNATURE}

$\frac{8 / 24 / 09}{\text { Date }}$

C:IDocuments and Settingslbcubbage.STOOGENET\Desktop\03.11.2009 GO Cart FIELD FORM.doc Page 3 of 3 